\title{
Microfluidic Devices for Forensic DNA Analysis:
}

\section{A Review}

\author{
Brigitte Bruijns ${ }^{1,2, *}$, Arian van Asten ${ }^{3,4}$, Roald Tiggelaar ${ }^{1}$ and Han Gardeniers ${ }^{1}$ \\ 1 Mesoscale Chemical Systems, MESA ${ }^{+}$Institute for Nanotechnology, University of Twente, Drienerlolaan 5, \\ Enschede 7500 AE, The Netherlands; r.m.tiggelaar@utwente.nl (R.T.); j.g.e.gardeniers@utwente.nl (H.G.) \\ 2 Life Science, Engineering and Design, Saxion University of Applied Sciences, M. H. Tromplaan 28, \\ Enschede 7513 AB, The Netherlands \\ 3 Netherlands Forensic Institute, Laan van Ypenburg 6, The Hague 2497 GB, The Netherlands \\ 4 Co van Ledden Hulsebosch Center, Amsterdam Center for Forensic Science and Medicine, \\ University of Amsterdam, Science Park-Building 904, Amsterdam 1098 XH, The Netherlands; \\ clhc-science@uva.nl \\ * Correspondence: b.b.bruijns@utwente.nl; Tel.: +31-53-489-3471
}

Academic Editor: Domenico Caputo

Received: 8 June 2016 ; Accepted: 25 July 2016 ; Published: 5 August 2016

\begin{abstract}
Microfluidic devices may offer various advantages for forensic DNA analysis, such as reduced risk of contamination, shorter analysis time and direct application at the crime scene. Microfluidic chip technology has already proven to be functional and effective within medical applications, such as for point-of-care use. In the forensic field, one may expect microfluidic technology to become particularly relevant for the analysis of biological traces containing human DNA. This would require a number of consecutive steps, including sample work up, DNA amplification and detection, as well as secure storage of the sample. This article provides an extensive overview of microfluidic devices for cell lysis, DNA extraction and purification, DNA amplification and detection and analysis techniques for DNA. Topics to be discussed are polymerase chain reaction (PCR) on-chip, digital PCR (dPCR), isothermal amplification on-chip, chip materials, integrated devices and commercially available techniques. A critical overview of the opportunities and challenges of the use of chips is discussed, and developments made in forensic DNA analysis over the past 10-20 years with microfluidic systems are described. Areas in which further research is needed are indicated in a future outlook.
\end{abstract}

Keywords: cell lysis; DNA extraction and purification; PCR; isothermal amplification reactions; microfluidics; chips

\section{Introduction}

The DNA analysis process at the forensic laboratory sometimes takes days, resulting in the fact that the outcome may have become less relevant to be able to effectively contribute to the initial phase of the criminal investigation, conducted by the police forces [1]. This might give a perpetrator time to eliminate relevant evidence, to disappear or even to commit another crime. On the other hand, it is desired to release innocent suspects quickly from custody [2]. The first hours of investigation are not without reason called the "golden hours". For these reasons, there is a strong need for relevant information becoming available as quickly as possible [3]. Devices that provide immediate information to police investigators at the crime scene are especially useful, as direct analysis contributes to fast and effective case scenario development.

So-called "lab-on-a-chip" (LOC) technology has the potential to be used for this purpose. An LOC can be defined as a device in which multiple laboratory techniques are integrated in a chip with a footprint of at most a few tens of square centimeters. An LOC comprises an enclosed internal 
microfluidic channel network with small characteristic dimensions below $1 \mathrm{~mm}$ in which reagents can be manipulated on the microscale. The internal volumes of LOCs are within the $\mu \mathrm{L}-$ range, resulting in typical microfluidic benefits, such as rapid heating and fast mixing. As a consequence, LOC devices offer fast analysis time, require minimal amounts of analyte and are portable. Due to sample handling in a sealed microfluidic environment, LOC systems reduce the risk of (cross-)contamination, improve the chain of custody and provide the possibility of direct analysis at the crime scene. LOCs are frequently designed for single use, which will bring benefits with respect to contamination risks and the chain of custody. All of these issues are important within forensic science.

To get from forensic trace sampling to useful forensic information, several steps can be distinguished, as can be seen Figure 1, in which the conventional techniques, as well as their existing microfluidic counterparts are listed. Ideally, devices are used that can collect a sample from the crime scene, perform sample work-up (lysis and extraction of DNA) and amplify and analyze the DNA. Since the first hours of an investigation are of utmost importance and usually the amount of time available to analyze the crime scene is limited, fast devices are crucial. However, in practice, such fully-integrated devices that can be applied directly at the crime scene are not realized yet. Microfluidic devices developed for point-of-care and clinical applications for cell lysis, sample work-up, PCR and detection/analysis create opportunities, which can also be applied within the forensic field.

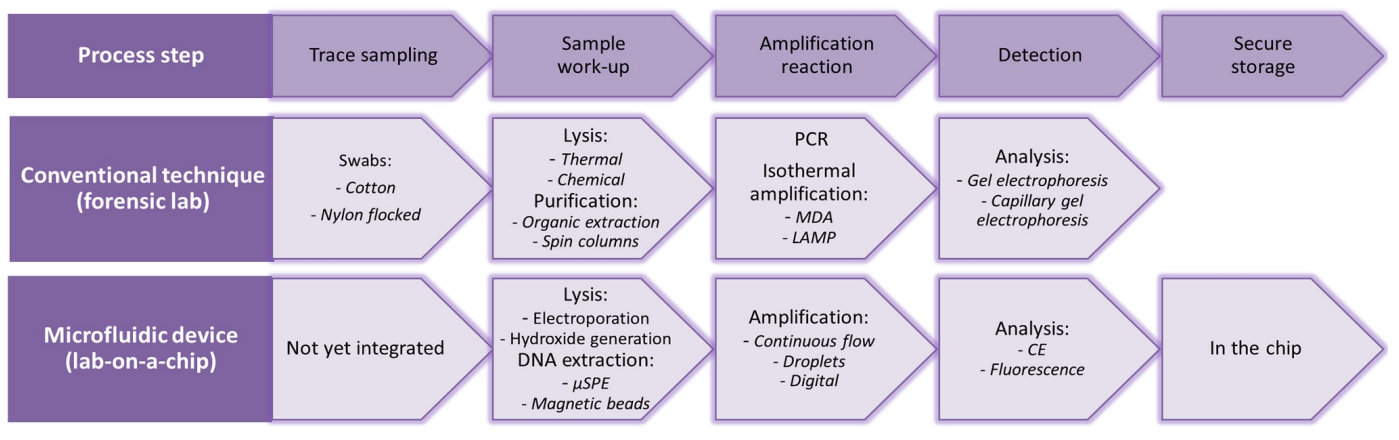

Figure 1. In the top row, the consecutive steps in the process of forensic DNA analysis are listed; within the middle row, the conventional technique with some examples. In the bottom row, microfluidic analogies can be found with some examples.

In this review, the latest developments for each step will be highlighted. Aspects to improve these microfluidic devices are discussed. Such a critical approach and considerations are a necessity to come to integrated devices for broad use. It will also be discussed at which level these steps have been integrated in a complete microfluidic forensic DNA analysis system. Besides the steps mentioned in Figure 1, also PCR speed records, the current status of DNA analysis on-chip (on the research level, as well as with commercial systems) and the opportunities and challenges of the use of chips are discussed.

\section{Trace Sampling}

Before DNA analysis can be carried out, the sample must be collected in an appropriate way, such that no contamination takes place and that as much sample as possible is collected. Careful selection of the samples by the forensic investigator is of utmost importance, since only a limited amount of samples can be sent to the laboratory for further analysis [1]. Not only samples from a crime scene, but also reference samples need to be taken in a proper way that is rapid and painless and least invasive for the person (suspect or victim). Typically, swabs are used for this purpose [4]. For the recovery of a sample from the crime scene, several different types of swabs can be used, with different structures, as shown in Figure 2. 


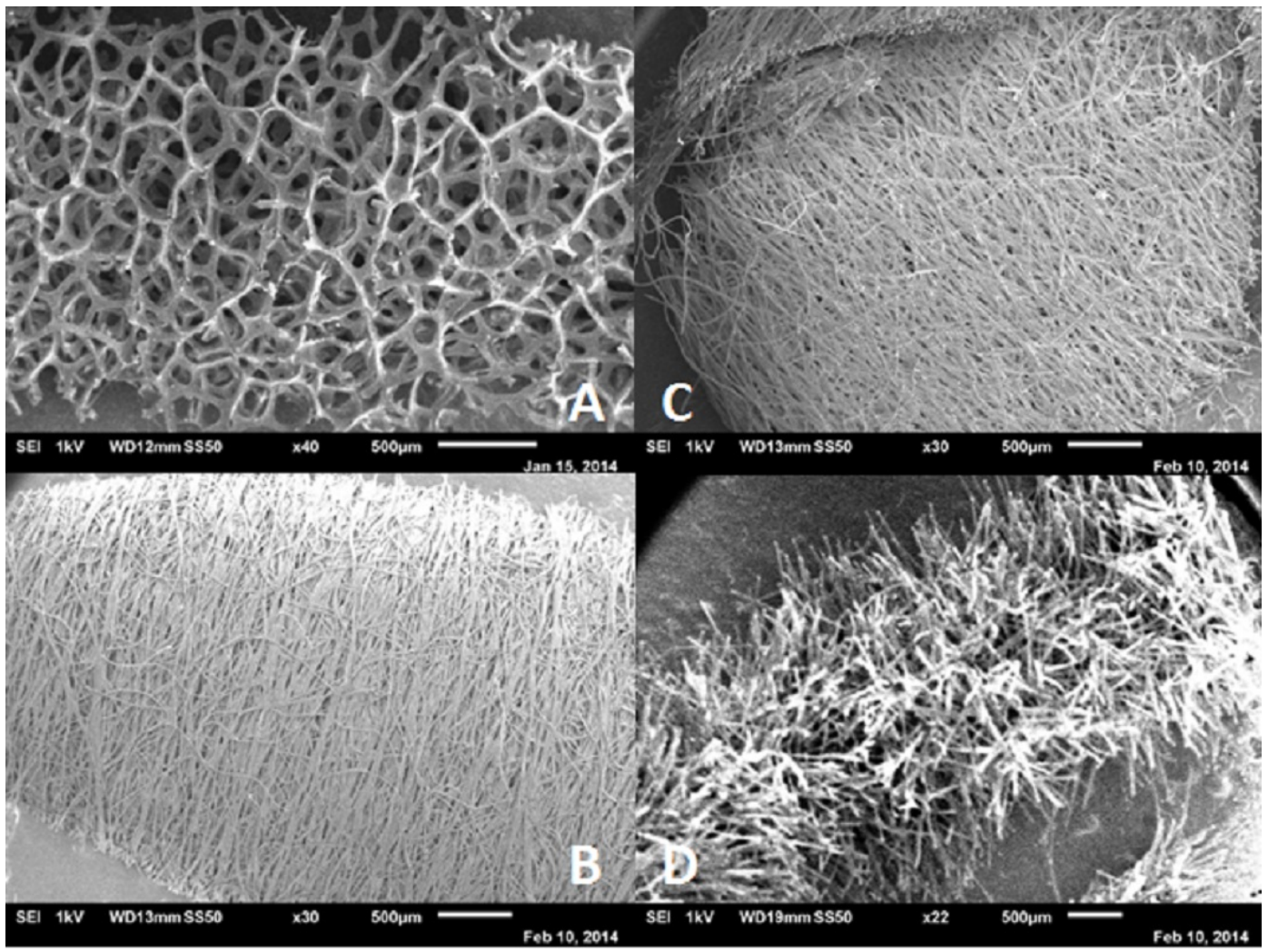

Figure 2. Scanning electron microscope images of several swab materials. (A) Foam swab (Sterile Foam Tipped applicator, Puritan); (B) rayon swab (155C Rayon, Copan); (C) polyester swab (159C Polyester, Copan); and (D) flocked swab (3503C 4 ng Floqswab, Copan).

In contrast to what is common practice in forensics, most existing micro-devices use cell lysate or pure DNA in a buffer as input material, because microfluidic devices require samples in a liquid solution. Only some commercially available devices, as discussed in Section 8.2, make use of a swab as input. Since flow channels in a chip are typically smaller than $1 \mathrm{~mm}$ in diameter, it is very important to prevent clogging, which can, for example, occur due to fibers from a swab. More specifically, new research is required to find out how many fibers swabs release upon forensic use, because this is crucial knowledge to judge their appropriateness for LOC-applications. Loading of the crime scene sample from a swab into a microfluidic device is another challenge that needs more attention in future research.

\section{Sample Work-Up}

The sample work-up usually consists of three steps: cell lysis, DNA extraction and DNA purification $[5,6]$. The last two steps are often combined when carried out on-chip. After lysis of the cells, the DNA must be separated from the other cellular components, since these can inhibit the amplification reaction [7]. Commonly present inhibitors in forensic samples are ethanol and sodium dodecyl sulfate (SDS) originating from the isolation technique, as well as hemoglobin, calcium-ions, melanin and urea, possibly present in biological samples. These inhibitors can result in a delay in the threshold cycle, reduction in the sensitivity of the detection (especially for larger amplicons) or even failure of PCR amplification [4].

\subsection{Cell Lysis}

To induce cell lysis (on-chip) thermal lysis, electrochemical lysis and mechanical lysis are some of the options [8,9]. Most of the methods and on-chip systems are already used within clinical settings, 
but are not (yet) applied within forensic applications. In fact, these lysis methods can also be utilized within forensic micro-devices and might give opportunities within forensic DNA analysis.

Thermal lysis is a popular method, as it is simple to integrate with other on-chip steps $[8,9]$. In the case that PCR will also be performed, the first temperature step in the program can be used to induce the lysis of the cells. Typically temperatures of $94{ }^{\circ} \mathrm{C}$ for $2 \mathrm{~min}$ are applied for lysis, followed by temperature steps necessary for PCR [10,11]. Wiederkehr et al. used for their on-chip PCR amplification of whole blood an extra temperature step prior to the PCR reaction of $2 \mathrm{~min}$ at $98^{\circ} \mathrm{C}$ [12]. A micro-device for the capturing and lysis of bacteria cells was developed by Tsougeni et al., in which cell lysis was obtained by applying $93-95^{\circ} \mathrm{C}$ for $10 \mathrm{~min}$ [13].

A lysis buffer containing surfactants can solubilize the lipid membrane of cells, which is known as chemical lysis [14]. Jen et al. used a lysis buffer with 1\% Triton X-100 for their microfluidic chip with an array of micro-wells [15]. The drawback of chemical lysis (on-chip) is the required washing step [9].

Applying high electric field pulses (around $1 \mathrm{kV} / \mathrm{cm}$ ) will induce an extra transmembrane potential in mammalian cells. Irreversible electroporation is a result of short (around $2 \mu \mathrm{s}$ ) high electric field strength pulses $(\geq 10 \mathrm{kV} / \mathrm{cm})$. The latter technique is used for the inactivation and pasteurization of cells, but also for cell lysis. The advantage is that no chemicals are needed [16]. Lu et al. have developed a microfluidic device for the electroporation of cells. About $74 \%$ of the cells could be lysed by applying a voltage of $8.5 \mathrm{~V}$ at a frequency of $10 \mathrm{kHz}$. With this method, cells were lysed in a continuous-flow device in small volumes with a lower power consumption than in conventional larger equipment [14]. Furthermore, Jiang et al. used an electric signal to lyse their cells; a $6.8 \mathrm{~V}$ square wave pulse resulted in a lysis efficiency of about 50\% [17].

Another lysis method is based on local hydroxide electro-generation, also known as alkaline or electrochemical lysis [9]. The hydroxide ions, by cleaving fatty acids, porate the cell membrane and open it permanently $[18,19]$. The hydroxide ions will be neutralized afterwards by the protons that are also generated by the electrochemical process [18]. The advantages of this method are the absence of detergents and heating elements [20]. Di Carlo et al. used a voltage of only $2.6 \mathrm{~V}(43 \mathrm{~V} / \mathrm{cm})$ [18]; Nevill et al. used a voltage of $2.5 \mathrm{~V}(11 \mathrm{~V} / \mathrm{cm})$ [19]; and $10 \mathrm{~V}$ was applied for $5 \mathrm{~min}$ by Lee et al. in order to achieve successful lysis [20].

Mechanical lysis uses nanostructured filter-like contractions (so-called nano-knives) in a microfluidic channel to lyse the cells. Mechanical lysis is a reagentless method, but only shear and frictional forces are usually not enough to induce rupture of the cell membranes. By integrating sharp nanostructures in the chip, which penetrate the cell membrane, successful lysis can be obtained [21].

Optically-induced cell lysis can also be performed in microfluidic systems. With this technique, a specific cell can be lysed, without damaging the nucleus. By applying an alternating current, a high electrical impedance is present in the lysis zone. When the beam spot illuminates this zone, the impedance decreases substantially, resulting in a nonuniform electric field, which induces a transmembrane potential [22]. Huang et al. applied this principle to lyse cells in their microfluidic device, and for about $78 \%$ of the cells, the membrane was lysed [23].

Other conventional (large scale) lysis methods, which are translated to on-chip techniques, are osmotic lysis and ultrasonic or acoustic lysis. These methods are not widely used within (forensic) microfluidics, due to the complexity of the methods. For osmotic lysis, a change in cell medium concentrations and a treatment step prior to the osmotic lysis to weaken the cells is required. With acoustic lysis, heat is generated, which can result in the transmission of energy to the cell medium [24].

A more extensive review of cell capturing and lysis methods in a chip is given by Le Gac et al. [9]. Fox et al. focus on electroporation of cells [16].

An upcoming field is single cell lysis on-chip. Since crime scene samples often contain only a few cells and little amounts of DNA, these methods are of great interest for future forensic developments. Most of the techniques are based on the cell lysis methods as described above, but with an additional cell entrapment system on the chip [25]. Especially single cell electroporation is a popular 
method [26-28]. Jen et al. have developed a chip for chemical lysis of single cells by using an array of micro-wells [15].

\subsection{DNA Extraction and Purification}

\subsection{1. $(\mu) \mathrm{SPE}$}

Solid phase extraction (SPE) by the use of silica is a commonly-used method for on-chip extraction, as it effectively binds the DNA $[6,29,30]$. Purification of nucleic acids (DNA or RNA) by $(\mu)$ SPE consists of a DNA loading, a washing and an elution step [8]. Only nanograms of silica resin in a $\mu$ SPE device are enough to adsorb and desorb DNA in the pg-ng range [30,31]. Tian et al. have given an overview of possible silica resins and suggest that fully-hydrated acidic silica resins provide the best solid phase for DNA binding, and the complete $\mu$ SPE procedure takes less than $10 \mathrm{~min}$ [30]. A sol-gel with enclosed silica beads can be used to purify the sample in a chip. In theory, silica beads and sol-gels can be used individually; however, the use of only silica beads shows the compression of the particles during use, and sol-gels are mechanically not very stable, which is a drawback of this method. Wolfe et al. suggest to use an acid-catalyzed sol-gel precursor solution combined with silica beads in order to obtain the best results. With this method, they could obtain PCR-amplifiable DNA [32]. Silica beads packed into a glass chip were used by Breadmore et al. to separate the DNA. The beads were immobilized in a sol-gel to provide a stable and reproducible solid phase. The additional advantage of this method is that they could reduce the extraction time from 25 to $15 \mathrm{~min}$ by using a $\mathrm{pH}$ of 6.1 instead of 7.6 as the loading conditions [33]. Duarte et al. named the DNA extraction on their chip with magnetic silica beads "dynamic SPE". They could recover more than $65 \%$ of DNA from $0.6 \mu \mathrm{L}$ of blood (lysis of the blood with detergents was performed off-chip), and the concentration of the resultant DNA was above $3 \mathrm{ng} / \mu \mathrm{L}$. After purification, they performed amplification of the DNA in the chip, and the PCR products were analyzed off-chip [34]. Reedy et al. designed a poly(methyl methacrylate) (PMMA) micro-device and used chitosan to bind DNA in a pH-dependent manner, i.e., binding at $\mathrm{pH} 5$ and release at $\mathrm{pH}$ 9. With this chip, they could purify a lysed whole blood sample, which turned out to be PCR amplifiable [7]. By using silica beads in their SPE chip, Zhang et al. obtained a DNA extraction efficiency of about $50 \%$ within $15 \mathrm{~min}$ [35].

\subsubsection{Magnetic Beads}

Magnetic beads provide a fast and efficient method for the purification of DNA from a large variety of (small quantity) forensic samples [8,36]. The ChargeSwitch ${ }^{\circledR}$ PCR clean-up kit from Invitrogen contains magnetic beads to purify the sample from salts, primers, dNTPs and other non-nucleic acid reagents. The charge of the beads depends on the $\mathrm{pH}$ of the buffer. At low $\mathrm{pH}$, the beads have a positive charge and will bind nucleic acids, since the nucleic acids have a negatively-charged backbone. By increasing the $\mathrm{pH}$ to about 8.5 , the nucleic acids can be eluted from the beads. The binding capacity is about $25 \mu \mathrm{g}$ DNA per $1 \mathrm{mg}$ beads [37]. Hopwood et al. used the ChargeSwitch ${ }^{\circledR}$ beads to purify the sample in their microfluidic system for rapid forensic DNA analysis [38]. Other commercially available magnetic beads are Dynabeads ${ }^{\circledR}$. These beads were used by Lien et al. for their reverse transcription-PCR (RT-PCR) micro-device [39]. Phase separation of magnetic beads from picoliter-scale droplets is used, as well, but this is difficult due to the high interfacial tension. Gu et al. used ferromagnetic particles to carry the magnetic beads to overcome this problem [40]. Yang et al. have developed a microfluidic cartridge for sample lysis by inserting a swab head into the lysis chamber. Buccal, saliva and blood swabs were lysed with $1 \mathrm{~mL}$ lysis buffer. Three different commercially available lysis buffers were used, all based on magnetic bead chemistry. The lysis efficiency of the cartridge was comparable to in-tube (benchtop) controls [41]. 


\subsubsection{Differential Extraction}

Differential extraction on-chip is still a challenge for forensic DNA analysis. Differential extraction means that the male and female DNA fractions must be separated, which is important for sexual assault evidence. In 2006, the group of Landers published an article about cell lysis and DNA extraction of sperm cells on-chip. Their chip is based on SPE with a microchannel partially packed with a sol-gel/bead mixture. The packed sperm cells are subsequently lysed with a lysis buffer, which takes about $15 \mathrm{~min}$. From the purified sample, it was possible to obtain a short-tandem repeat (STR) profile [42]. In 2009, the same group published an article about differential extraction by means of acoustics. They could obtain from mock cases within 14 min highly purified male and female fractions. By the use of ultrasound, the device could selectively trap the sperm cells from a sample that also contained female epithelial cell lysate [43]. Microfluidic Systems, Inc., presented their device at the 9th International Conference on Miniaturizes Systems for Chemistry and Life Sciences in 2005 and patented the design; however, they never published progress or results in a journal. To obtain the separated fractions, they apply sonication to selectively lyse the epithelial cells combined with a filter to separate the epithelial cells from the sperm cells. This method is fully automated and takes less than three hours [44,45]. Landers et al. suggested also another mechanism to separate the fractions. This method makes use of the different physicochemical properties of the two fractions, which result in different sedimentation rates [46].

The use of packed silica beads is a well-established and relatively simple concept, but this technique uses compounds that can inhibit the amplification reaction, which is also the case for sol-gels with silica beads. By using paramagnetic beads, this problem can be overcome, but places restrictions on the device material and dimensions [29]. $(\mu) \mathrm{SPE}$ is integrated on-chip by several research groups, and by the use of $(\mu) \mathrm{SPE}$, whether or not combined with beads, it is possible to obtain a PCR amplifiable DNA extract. However, it is not yet widely applied for DNA analysis in a microfluidic device for forensic applications, which is also emphasized in Section 8 of this review. In recent publications, silica beads were the method of choice for SPE extraction $[47,48]$. Although magnetic beads can be used as a fast purification method and can be used in chips for forensics as the extraction method, the control of the beads remains complex [38]. Differential extraction is very important in, for instance, rape cases, but the various methods for on-chip extraction have not yet been applied within a micro-device that combines all of the steps of forensic DNA analysis.

\section{DNA Amplification}

Forensic samples are known for the low amount of DNA available, as one cell only contains about 6 pg of DNA [49]. Therefore, it is necessary to perform an amplification reaction to increase the amount of DNA, such that detection and further analysis (e.g., STR profiling) can take place. In order to analyze samples directly at the crime scene, a fast and reliable amplification technique is required. PCR is widely used for STR profiling of DNA samples. Most of the microfluidic devices described in this section are solely PCR chips. Confirmation of the functionality of the chip is carried out by non-specific detection by the use of a fluorescent intercalating dye to evidence DNA amplification or by off-chip gel electrophoresis to determine the amplicon length. Implementation of STR-profiling is still a challenge and is only done by a few research groups and commercial companies, which will be discussed in Section 8. Nowadays, also other methods, such as isothermal amplification techniques, are forthcoming.

\subsection{PCR}

Before amplification, usually a quantification step is included within conventional STR profiling, since the best results are obtained by the use of a specific amount of DNA input. Quantification ensures the maximum efficiency of the amplification reaction, and the (repetitive) analysis of over-amplified samples is prevented [50]. Fluorescent DNA dyes (such as PicoGreen) and slot blot are some of the 
methods that can be used to detect and quantify DNA within a sample. However, these techniques are not human-specific or are labor intensive and, therefore, became outdated [51]. Real-time PCR is nowadays the method of choice, which is mostly based on the use of the Alu sequences in the human genome. It is even possible, by real-time PCR, to quantify not only the total human autosomal DNA, but also Y-chromosomal and mitochondrial DNA [52].

However, most of the developed micro-devices are designed for either sample work-up or amplification and detection, whereby the input DNA has a known concentration. Therefore, DNA quantification on-chip has not been widely incorporated. In order to overcome the need for quantification, a silica filter or beads can be used, which have a specific binding capacity to prevent an excess of DNA available for the amplification reaction [53,54].

Within the polymerase chain reaction (PCR), the annealing and the extension step can be combined, if primer design allows, an operation often seen within microfluidics [55]. With conventional thermocyclers, a heating and cooling rate of about $2-3{ }^{\circ} \mathrm{C} / \mathrm{s}$ can be obtained [5].

In the past decade, a wide variety of microfluidic devices for DNA amplification has been developed. In microfluidic devices, heating and cooling rates of at least $10-50{ }^{\circ} \mathrm{C} / \mathrm{s}$ can be obtained [5,56]. The micro-devices can be divided into two main types: well-based and continuous-flow PCR chips [57]. Examples of these different types of chips can be seen in Figures 3 and $4[56,58-60]$.

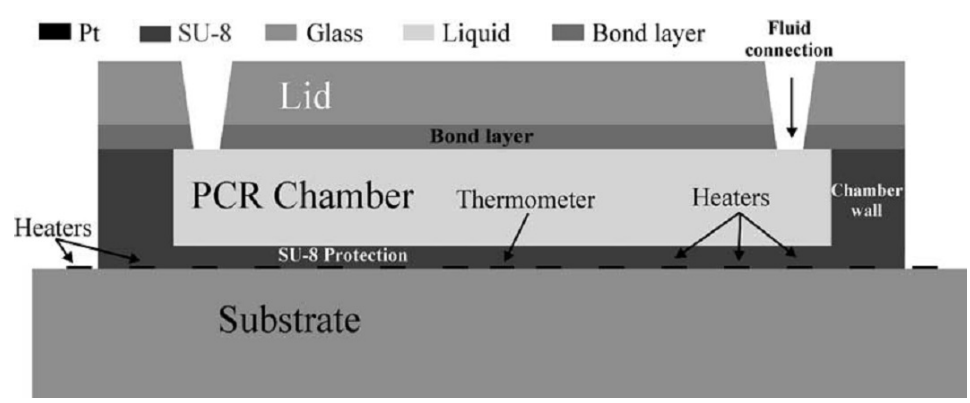

Figure 3. Example of a well-based chip for DNA amplification (reprinted from [56], with permission from Elsevier).
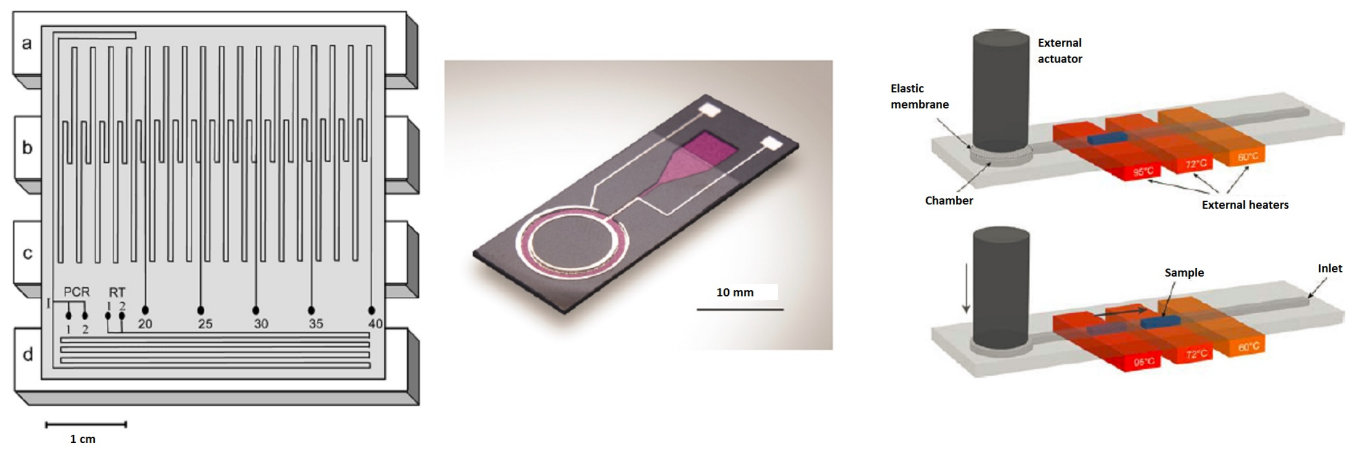

Figure 4. Examples of continuous flow chips with, from left to right, a fixed-loop (reprinted with permission from [58], Copyright 2003 American Chemical Society), a closed-loop (reproduced from [59] with permission of The Royal Society of Chemistry) and an oscillatory chip (reprinted from [60] with kind permission from Springer Science and Business Media) for DNA amplification: Principle of sample shuttling: The PCR reaction is performed inside a straight channel ending in a chamber with a membrane that is deflected to move the liquid sample back and forth over three constantly-heated regions. Actuation and heating is done externally, so that the chip can be kept as simple as possible.

For continuous-flow chips, the sample must be moved through fixed temperature zones to perform thermal cycling. In contrast to well-based systems, only the sample needs to be heated 
and cooled, and not the entire chip. In 2009, Zhang et al. gave an overview of microfluidic DNA amplification devices that were developed at that time. Most of the devices were continuous-flow PCR chips with a fixed-loop design [57]. An overview of the variety of well-based and continuous-flow PCR chips and their characteristics can be found in Table 1. Besides the number of cycles, also the type and/or length in base pairs (bp) of the amplicon is given and the total cycling time.

Table 1. Overview of various PCR chips. CE, capillary electrophoresis.

\begin{tabular}{|c|c|c|c|c|}
\hline Type & Material & Cycles* & Detection & Year and Ref. \\
\hline \multirow{4}{*}{ Well-based } & SU-8 & $\begin{array}{l}\text { Melting curve experiment } \\
35 \text { (199 bp, } 90 \mathrm{~min})\end{array}$ & $\begin{array}{l}\text { SYBR Green (melting curve) } \\
\text { Electropherogram (off-chip) }\end{array}$ & (2004) [56] \\
\hline & $\begin{array}{l}\text { PDMS/Glass } \\
\text { (droplet array) }\end{array}$ & 40 (several amplicons, $65 \mathrm{~min}$ ) & $\begin{array}{l}\text { EvaGreen } \\
\text { (real-time + melting curve) }\end{array}$ & (2009) [61] \\
\hline & $\begin{array}{l}\text { Silicon } \\
\text { (droplet array) }\end{array}$ & $\begin{array}{l}45(18-25 \mathrm{bp}, 65 \mathrm{~min}+66 \mathrm{~min}) \\
\text { micro RNA, RT-PCR }\end{array}$ & TaqMan probes (real-time) & (2011) [62] \\
\hline & Polycarbonate & 32 (243 and $96 \mathrm{bp}, 45 \mathrm{~min})$ & CE (on-chip) & (2016) [63] \\
\hline \multirow{5}{*}{ Fixed-loop } & Glass & 20 (176 bp, 1.5-19 min) & Gel + EtBr (off-chip) & (1998) [64] \\
\hline & Glass & $\begin{array}{l}20,25,30,35 \text { and } 40 \\
(230 \mathrm{bp}, 17 \text { min for } 40 \text { cycles })\end{array}$ & SYBR Green (off-chip) & (2003) [65] \\
\hline & PMMA & 20 (990 bp, $57 \mathrm{~min})$ & Gel + EtBr (off-chip) & (2009) [66] \\
\hline & Pyralux & 30 (90 bp, $5 \mathrm{~min})$ & Gel + EtBr (off-chip) & (2014) [67] \\
\hline & FEPtubing & $\begin{array}{l}40 \text { (Plasmid clones and } \\
\text { Escherichia coli } 40 \mathrm{~min} \text { ) }\end{array}$ & TaqMan probes & (2014) [68] \\
\hline \multirow{2}{*}{ Closed-loop } & Ceramic & 40 (209 bp, 27-70 min) & Electronic & (2003) [69] \\
\hline & Teflon & 35 (305 and $700 \mathrm{bp}, 73 \mathrm{~min}$ ) & Gel + EtBr (off-chip) & (2004) [70] \\
\hline \multirow{4}{*}{ Oscillatory } & Silicon/Pyrex & 20-30 (only theoretical model) & Gel + EtBr (off-chip) & (2003) [71] \\
\hline & Silicon & 35 (Human papillomavirus, $15 \mathrm{~min}$ ) & Gel + EtBr (off-chip) & (2005) [72] \\
\hline & PDMS & 12(-20) (Plasmid DNA, 3-4 min) & SYBR Green & (2007) [60] \\
\hline & PDMS/Glass & 30 (Hepatitis B virus, $23 \mathrm{~min}$ ) & TaqMan probe & (2014) [73] \\
\hline
\end{tabular}

${ }^{*}$ Cycle time including initial denaturation and final extension, if used. If no amplification time were given, the total time of the PCR protocol was taken.

The upcoming field of interest is the principle of PCR in droplets. By the use of droplets, the analysis time can be shortened, and each droplet can be seen as an individual reaction volume [57]. In the following subsection well-based chips, continuous-flow designs, as well as PCR within droplets will be discussed.

\subsubsection{Well-Based Chips}

In a well-based PCR system, the well, or even the complete chip, is sequentially cooled and heated during the PCR temperature cycles. The disadvantage of such a system is the long cycling time, due to the large total thermal mass of the system [57].

El-Ali et al. have modeled and developed a well-based chip that can reach heating and cooling rates up to 50 and $30{ }^{\circ} \mathrm{C} / \mathrm{s}$, respectively, using integrated heaters. The chamber can contain a volume of $20 \mu \mathrm{L}$ and is made of SU-8 on a glass substrate [56].

A chip with nanoliter wells for real-time quantitative PCR amplification has been developed by Liu et al. The polydimethylsiloxane (PDMS) chip consists of 100 wells of $120 \mathrm{~nL}$ with pre-loaded dried primer pairs. Cycling was carried out with a thermoelectric cooler, and the fluorescent dye EvaGreen was used for the detection of the PCR product [61].

Zhang et al. have developed a well-based chip with a nanoliter droplet array for RNA amplification. By using a TaqMan ${ }^{\circledR}$ probe, the amplification process could be monitored in real-time [62]. 


\subsubsection{Continuous-Flow Chips}

Continuous-flow chips are divided into fixed-loop, closed-loop and oscillatory chips. Each type of method has its own advantages and disadvantages, which will be discussed below.

\section{Fixed-Loop Chips}

A fixed-loop system contains zones with different temperatures through which the sample is moved. The number of thermal cycles is fixed by the amount of meanders in the design, and the timing of each step is typically controlled by the length of the meander in a specific temperature zone [57].

Kopp et al. have developed the first continuous-flow PCR chip. By changing the flow rate, the total reaction time varies between $90 \mathrm{~s}$ and $18.7 \mathrm{~min}$, although a faster protocol results in less PCR product [64]. A PMMA chip has been developed by Qi et al. to amplify an amplicon of 990 base pairs. The chip, based on the design of Kopp et al, consists of 20 thermal cycles for a PCR mixture of $10 \mu \mathrm{L}$ [66].

Obeid et al. have developed a continuous-flow chip (Figure 4 on the left) for DNA and RNA amplification in combination with laser-induced fluorescence (LIF) detection and SYBR Green I. The denaturation, annealing and extension steps were carried out in time ratios of 4:4:9. The product can be analyzed after 20, 25, 30, 35 and 40 cycles, which gives with a flow rate of $1.26 \mu \mathrm{L} / \mathrm{s}$ and a total cycle time of 5, 6, 7, 8 and 9 min, respectively. The smallest amount of DNA they could detect was $50 \mathrm{fg}$ [65]. In another publication, Obeid et al. showed that the complete process from sample injection to product collection after amplification takes $35 \mathrm{~min}$. By using hand-driven injection, the reaction of a $10-\mu \mathrm{L}$ sample could be completed (30 cycles) within 6 min [58].

\section{Closed-Loop Chips}

In a closed-loop chip, the sample must be moved through a fixed circuit, whereby the number of thermal cycles can vary [57].

West et al. have developed a closed-loop chip (Figure 4 in the middle) in which a cycle time of three minutes or less is possible. Movement of the fluid was performed by using magnetohydrodynamic actuation using a 1-kHz AC signal. A two-step PCR reaction was carried out successfully, although the authors of the article recommend a three temperature zone design to provide more flexibility [59].

The heating required for the PCR was used by Chen et al. to induce fluid motion by Rayleigh-Bénard convection, such that there was no pump required. They developed a Teflon tube loop-based reactor with three heating zones. The reactor loop is put at an angle with respect to the horizontal plane to create convection. Successful amplification of a 305- and a 700-bp fragment could be carried out within 35 cycles with a total reaction time of 73 min (including the final extension of $7 \mathrm{~min}$ ). However, the shorter amplicon showed a higher amplification efficiency than the longer amplicon [70].

\section{Oscillatory Chips}

The number of cycles can be varied in an oscillatory system. The different chambers on the chip are held at different temperatures, and the sample is shunted back and forth between these chambers [57].

Bu et al. developed a design with a bi-directional peristaltic pump to shunt the sample back and forth between three chambers with different temperatures. A droplet of only $1 \mu \mathrm{L}$ could be operated, which can be heated and cooled to the desired temperature in less than $1 \mathrm{~s}$ with this design using integrated heaters. However, no real PCR chip has been made; Bu et al. only proposed a design and a theoretical evaluation in their article [71].

By shunting a sub-microliter sample back and forth between three temperature zones (Figure 4 on the right), Frey et al. could combine the cycling flexibility of a chamber-type device with the fast 
principle of continuous-flow devices. The chip was designed as a disposable device for quantitative PCR reactions. Successful real-time amplification could be carried out in less than 5 min [60].

\subsubsection{PCR Speed Records}

For several years, there has been an on-going competition regarding the record for fastest on-chip amplification. Giordano et al. claimed in 2001 that their well-based chip could perform DNA amplification within $240 \mathrm{~s}$. They used a 500-bp amplicon, and a PCR product was observed after 15 cycles ( $15 \mathrm{~s}$ per cycle). Temperature control was carried out with a thermocouple within the 1.7- $\mu$ L PCR chamber [74]. In 2006, Neuzil et al. published two papers about their ultra-fast real-time well-based PCR micro-device [75,76]. One thermal cycle was conducted in $8.5 \mathrm{~s}$, which means they could complete 40 cycles in $340 \mathrm{~s}$. However, the length of their amplicon was only 83 bp [75]. In 2011, Fuchiwaki et al. claimed to have the fastest PCR chip, which makes use of continuous-flow, in the world. The 40 cycles could be completed, with a fluorescence level of $15 \%$, in only $120 \mathrm{~s}$. However, an $80 \%$ amplification/yield was obtained after $600 \mathrm{~s}$ [77]. Son et al. achieved similar results (30 cycles within $5 \mathrm{~min}$ ) by using a thin Au film and light emitting diodes as a light-to-heat convertor and a heat source, respectively. A 98-bp amplicon could be successfully amplified with this photonic system [78]. They reduced the amplification time to 4 min for 30 thermal cycles for a 116-bp amplicon with an optofluidic cavity PCR device [79]. Most records were obtained by the use of a relatively short amplicon and optimal conditions (e.g., high DNA input and optimal primer concentrations). Therefore, it is questionable if such timescales are realistic for forensic applications, since with STR profiling amplicons can be $200 \mathrm{bp}$ in length or even more and usually real crime scene samples contain a low amount of DNA.

\subsubsection{PCR in Droplets}

Droplet-based microfluidics is an upcoming field of research. Reactions can be performed in water-in-oil droplets (biphasic) in microchannels, whereby each droplet functions as an independent reactor (pico- to nano-liter size), as can be seen in Figure 5. Droplet-based microfluidics offers several unique advantages when compared to conventional and single-phase continuous flow techniques, since less sample and reagents are required and no interaction with the channel walls takes place, because the droplets are isolated by the carrier fluid. High surface-to-volume ratios lead to shorter heat and mass transfer times and increase the mixing efficiency, making the system faster, and by using meandering channels, mixing can be even more efficient. The droplets are separated sample plugs, which prevent (cross-)contamination [57,80-84].

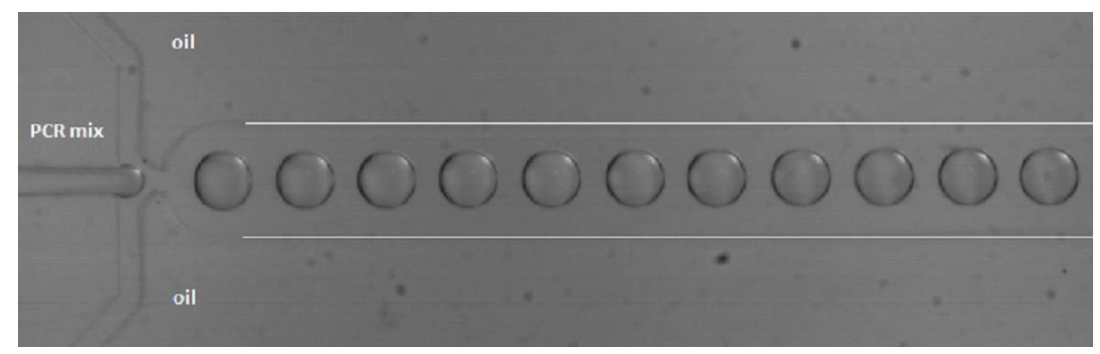

Figure 5. Droplet generation in a flow focus chip from PDMS with a channel width and height of 200 and $104 \mu \mathrm{m}$, respectively. The flow rates of the water and oil phase were 0.1 and $5 \mu \mathrm{L} / \mathrm{min}$, respectively. The white lines indicate the channel walls.

Several groups have developed a chip for DNA (and RNA) amplification in nano- to pico-liter droplets. An overview of several chips for droplet amplification and their characteristics is given in Table 2. Besides material choice, the number of cycles (with type/length of the amplicon) and the detection method, the droplet size is given. 
Table 2. Overview of various droplet PCR chips.

\begin{tabular}{cccccc}
\hline Type & Material & Cycles $^{*}$ & Droplet Size & Detection & Year and Ref. \\
\hline \multirow{4}{*}{ T-junction } & Silicon/Pyrex & 40 (unknown amplicon, $108 \mathrm{~min})$ & $8-15 \mathrm{pL}$ & FAM & $(2007)[85]$ \\
& Polycarbonate & $32(60 \mathrm{bp}, 14-19 \mathrm{~min})$ & $100-155 \mu \mathrm{m}$ & Fluorescence & $(2007)[86]$ \\
& SU-8/PMMA & $34(85 \mathrm{bp}, 17 \mathrm{~min})$ & $131 \mathrm{pL}$ & Gel + SYBR Green (off-chip) & $(2009)[87]$ \\
\hline \multirow{5}{*}{ Flow focus } & PDMS/Glass & $34(245 \mathrm{bp}, 35 \mathrm{~min})$ & $65 \mathrm{pL}$ & FAM and Alexa Fluor 594 & $(2008)[88]$ \\
& Glass & $25(101 \mathrm{bp}, 46 \mathrm{~min})$ & $3 \mathrm{~nL}$ (agarose) & SYBR Green (off-chip) & $(2010)[89]$ \\
& PDMS & $40-45(150-300 \mathrm{bp}, 30-90 \mathrm{~min})$ & $50 \mathrm{pL}$ & FAM & $(2011)[90]$ \\
& Glass & $25($ several amplicons, $46 \mathrm{~min})$ & pL (agarose) & SYBR Green (off-chip) & $(2012)[91]$ \\
& PDMS/Glass & $32(\mathrm{STR}, 152 \mathrm{~min})$ & nL (agarose) & CE (off-chip) & $(2014)[92]$ \\
\hline
\end{tabular}

* Cycle time including initial denaturation and final extension, if used. If no amplification time were given, the total time of the PCR protocol was taken. 
A numerical and experimental study of a droplet-based PCR chip to carry out a two-step PCR reaction was carried out by Mohr et al. The thermal conductivity and density of the aqueous and oil phase should not change too much in the PCR temperature range to ensure optimal thermal properties. Mohr et al. showed numerically that the variation is less than $3 \%$ and $4 \%$ for water and oil, respectively, when temperatures of 60 and $95^{\circ} \mathrm{C}$ are used [86].

Beer et al. have developed a microfluidic real-time PCR instrument for generating monodisperse microdroplet reactors, including thermal cycling for PCR and detecting real-time amplification in the individual picoliter droplets. Before thermal cycling of the PCR starts, an off-chip valving system stops the flow of droplets, after which the droplets remain stationary during the entire PCR reaction. The reactor size is six orders of magnitude smaller ( $p L$ instead of $\mu \mathrm{L}$ ) than commercial real-time PCR systems, and an approximately 56\% cycle reduction can be acquired. Only 18 cycles are required for single-copy real-time detection on the chip by the use of TaqMan-based FRET probes [85]. The same research group also developed a picoliter droplet chip for RNA isolation followed by RT-PCR. The process of amplification can be followed in real-time by fluorescence. Only 23 cycles are needed for single-copy reverse transcription from RNA, amplification and detection on-chip using TaqMan-based probes [93].

Kiss et al. have developed a continuous-flow device in which the oil stream guides the droplets through different temperature zones within $55 \mathrm{~s}$. Within $35 \mathrm{~min}$, they can detect a 245-bp Adenovirus product with one template molecule per 167 droplets, which is as low as $0.003 \mathrm{pg} / \mu \mathrm{L}$ [88].

Hatch et al. have developed a digital droplet chip, which can generate more than one million monodisperse $50 \mathrm{pL}$ in 2-7 min. The two-step PCR takes about $65 \mathrm{~min}$ with a total of 40-45 cycles. By using FAM probes, the amplification reaction can be monitored in real-time [90].

A radial PCR device with a hot zone for denaturation of the DNA and an annealing/extension zone has been developed by Schaerli et al. The amplification efficiency of a short 85-bp amplicon is about 20-fold higher than a long amplicon of $505 \mathrm{bp}$. With the design, a droplet formation frequency of $15 \mathrm{~Hz}$ can be obtained with a residence time of $29 \mathrm{~s}$ per cycle [87].

The agarose droplet method, developed by Yang et al., can be used for single molecule emulsion (RT-)PCR and amplicon trapping. The agarose droplets are gelated to form agarose beads after amplification. Ultra-low gelling agarose was used with a melting and a gelling point of $56{ }^{\circ} \mathrm{C}$ and $16^{\circ} \mathrm{C}$, respectively. This means that the agarose is in the liquid phase when the temperature is $\geq 16{ }^{\circ} \mathrm{C}$, and once solidified, the beads stay solid till $\leq 56{ }^{\circ} \mathrm{C}[89,91,94]$. Geng et al. designed a method for multiplex STR-typing at the single-cell level by the use of agarose droplets and a microfluidic device. The method is based on several consecutive steps (such as two PCR steps), which are not all performed on-chip. The total analysis time, from cell lysis up to capillary electrophoresis (CE) detection, is $22 \mathrm{~h}[92,95]$.

\subsection{5. dPCR}

Digital droplet PCR is the latest alternative method for the conventional real-time quantitative PCR technique. With limiting dilution, the sample can be divided into separate reaction chambers, whereby position statistics can be applied [96]. In 1992, Sykes et al. suggested a method to quantitate the total number of initial targets that are present in a sample. The sample, together with the PCR mixture, is divided into a large number of separate small volume reactions. Some of these small reaction volumes will contain a target molecule, and others will be empty. A reaction with a target molecule can be counted as ' 1 ' (positive) and without target molecule as ' 0 ' (negative), and therefore, the total number of positive reactions can be used for the quantification of the original sample. By separating the original sample into a high amount of small volumes, Poisson statistics can be used [97].

The well-based chips of Liu et al. and Zhang et al. are also digital PCR devices for real-time quantitative PCR [61,62]. The one million droplet array of Hatch et al. is an example of a micro-device that makes use of droplet PCR, as well as digital PCR [90]. White et al. used the digital PCR chip from Fluidigm in combination with TaqMan PCR for the absolute quantification of sequencing libraries [98]. 
Furthermore, Sanders et al. used this microfluidic device to perform quantitative PCR with less than 200 DNA copies, and they obtained reproducible results with high precision [99]. A droplet digital PCR device has been used by Wang et al. to perform absolute quantification of microRNA, which is lung cancer related [100].

\subsection{Isothermal Amplification}

For isothermal amplification reactions, there is no need for thermal cycling, which makes the (micro-)systems for isothermal amplification simpler and less energy-consuming, which is attractive for portable battery-operated instruments. Another characteristic of isothermal reactions is that the rate of the enzyme activity is the limiting factor instead of the rate of thermal cycling, as with PCR. Miniaturized systems can be composed of one microchamber, and no fluid motion is required during the amplification [101].

Just as with PCR, it is possible to perform real-time quantification of amplification products with fluorescent DNA probes or intercalating dyes. Whereas several inhibitors are known for PCR (e.g., heme, heparin, urea and acidic polysaccharides), isothermal techniques do not suffer from many of these inhibitors [102].

Enzymes that perform strand displacement are used within isothermal amplification methods. Therefore, no heating step is necessary to denature the DNA from double-stranded to single-stranded DNA [102]. $\quad$ 29 DNA polymerase is such a polymerase with strand displacement activity. Moreover, $\phi 29$ shows proof-reading activity and is capable of generating very long synthesis products [103].

Loop-mediated isothermal amplification (LAMP) and multiple displacement amplification (MDA) are examples of isothermal reactions. An overview of these and some other isothermal techniques, namely helicase-dependent isothermal DNA amplification (HDA), rolling circle amplification (RCA) and strand displacement amplification (SDA), is given in Table 3 [101,102,104]. These isothermal techniques are mentioned in the review of Auroux et al., who only mentioned two on-chip examples, without information on the integration of these techniques into microfluidic devices [55]. In 2008, Gill et al. described several isothermal amplification techniques in their article. They explained among others the methods SDA, RCA, LAMP and HDA [104]. In 2011, Asiello et al. gave an overview of several isothermal amplification methods, such as LAMP, HDA and recombinase polymerase amplification (RPA), and their applications in miniaturized systems [101]. A critical review about isothermal techniques for point-of-care applications was given in 2012 by Craw et al. [102]. Recently, Safavieh et al. reported an extensive overview of microchip and micro-device technologies for amplification by LAMP [105].

An overview of various isothermal amplification chips is given in Table 4. Below, some details of the two most studied methods, LAMP and MDA, are given. 
Table 3. Overview of various isothermal amplification methods. LAMP, loop-mediated isothermal amplification; MDA, multiple displacement amplification; HDA, helicase-dependent isothermal DNA amplification; RCA, rolling circle amplification; SDA, strand displacement amplification.

\begin{tabular}{|c|c|c|c|c|c|}
\hline Method & Polymerase & Temperature & Primers & Speed/Yield & Remarks \\
\hline LAMP [106,107] & Bst & $60-65^{\circ} \mathrm{C}$ & 2 or 3 sets & $\begin{array}{c}10-20 \mu \mathrm{g} \text { in } 30-60 \mathrm{~min} \\
10^{9} \text { copies }<1 \mathrm{~h} \\
\text { 3-fold every half cycle }\end{array}$ & $\begin{array}{c}\text { Highly specific } \\
\text { Detection by turbidity } \\
\text { Complex primer design }\end{array}$ \\
\hline MDA $[108,109]$ & $\phi 29$ & $30^{\circ} \mathrm{C}$ & Random hexamers & Exponential amplification & $\begin{array}{c}\text { High processivity } \\
\text { Direct amplification of lysate } \\
\text { (no purification) }\end{array}$ \\
\hline HDA [110-112] & Helicase & $\begin{array}{l}37^{\circ} \mathrm{C} \text { (mesophilic) } \\
60-65^{\circ} \mathrm{C} \text { (thermophilic) }\end{array}$ & 1 set & $\begin{array}{l}10 \mathrm{ng} \text { from } 10^{3} \text { copies } \\
\text { Exponential amplification }\end{array}$ & $\begin{array}{c}\text { UvrD helicase has } \\
\text { limited speed and processivity } \\
\text { Helimerase is more efficient }\end{array}$ \\
\hline RCA $[103,113,114]$ & ф29 Klenow & $37^{\circ} \mathrm{C}$ & $\begin{array}{c}1 \text { or } 2 \\
\text { primers }\end{array}$ & $\begin{array}{l}53 \text { nucleotides } / \mathrm{s} \\
70 \mathrm{kbp} \text { in } 20 \mathrm{~min}\end{array}$ & $\begin{array}{l}\text { Circular template needed } \\
\text { Can be used with padlock probes }\end{array}$ \\
\hline SDA [115] & exo $^{-}$Klenow & $37^{\circ} \mathrm{C}$ & 1 set & $\begin{array}{c}\text { Exponential amplification } \\
10^{10} \text {-fold } \\
10^{6} \text {-fold after } 5 \mathrm{~h}\end{array}$ & $\begin{array}{l}\text { Inefficient at long amplicons } \\
\text { Denaturation needed } \\
\text { Complex primer design }\end{array}$ \\
\hline
\end{tabular}


Table 4. Overview of various isothermal amplification chips. RPA, recombinase polymerase amplification.

\begin{tabular}{|c|c|c|c|c|c|}
\hline Method & Material & Amplicon & Volume & Detection & Year and Ref. \\
\hline \multirow{4}{*}{ LAMP } & Silicon & Virulence genes (various, $20 \mathrm{~min}$ ) & $50 \mu \mathrm{L}$ (10 chambers) & Turbidity and SYBR Green & (2011) [116] \\
\hline & PDMS & $\lambda \mathrm{DNA}(48,502 \mathrm{bp}$ input, $70 \mathrm{~min})$ & $2 \mu \mathrm{L}$ (for nL droplets) & Calcein & (2012) [117] \\
\hline & PDMS/Glass & Virulence genes (various, $60 \mathrm{~min}$ ) & $30 \mathrm{~nL}$ droplets & EvaGreen & (2013) [118] \\
\hline & PMMA & Salmonella $(-, 70 \mathrm{~min})$ & $25 \mu \mathrm{L}$ & SYBR Green & (2016) [120] \\
\hline \multirow{2}{*}{ MDA } & PDMS & E. coli (whole genome, $10-16 \mathrm{~h}$ ) & $60 \mathrm{~nL}$ & SYBR Green (off-chip) & $(2007)[121]$ \\
\hline & PDMS & MCF-7 cells (whole genome, $16 \mathrm{~h}$ ) & $1.4 \mathrm{~nL}$ & qPCR (off-chip) & (2015) [122] \\
\hline \multirow{2}{*}{ RCA } & Glass & $16 \mathrm{~S}$ rDNA (various, $110 \mathrm{~min}$ ) off-chip amplification & $30 \mu \mathrm{L}$ & SPR-Biosensor & (2014) [124] \\
\hline & Glass & OLR1 gene $(-, 30 \mathrm{~min})$ & $500 \mathrm{~nL}$ & EvaGreen & $(2015)[125]$ \\
\hline \multirow{3}{*}{ RPA } & Various & E. coli (bla $C T X-M-15$ gene, $15 \mathrm{~min})$ & $270 \mathrm{~nL}$ & Cy5 labeled probes & (2015) [126] \\
\hline & DVD-R discs & Various $(-, 2 \mathrm{~h})$ & $3 \mu \mathrm{L}$ (sample volume) & Optical density & (2016) [127] \\
\hline & PMMA/Glass & 2 viruses and 1 bacterium $(142,144$ and $181 \mathrm{bp}, 48 \mathrm{~min})$ & $54 \mu \mathrm{L}$ & Luminol & (2016) [128] \\
\hline
\end{tabular}




\subsubsection{LAMP}

LAMP is an isothermal nucleic acid amplification method with high specificity, efficiency and speed $[117,129]$. When Bst polymerase is used, the reaction can be carried out at $60-65^{\circ} \mathrm{C}[106,129,130]$. By using this technique, the target sequence is amplified three-fold every half 'cycle' [130]. Within $1 \mathrm{~h}$, a few copies of DNA can be amplified by LAMP up to a detectable amount [129]. Mori et al. claimed that $10-20 \mu \mathrm{g}$ is produced within 30-60 min [106], and Notomi et al. obtained $10^{9}$ copies in less than an hour [130].

Four or six specially-designed primers are required, as well as a polymerase with strand displacement activity (e.g., Bst polymerase). The loop primers (two) increase the speed of the (start of) the reaction, but are not essential $[106,129]$. The two outer primers are only used in the first steps; thereafter, only the inner primers are used. The correct primer design for the LAMP reaction is complicated and challenging [130]. The product, a mixture of stem-loop DNAs with various sizes of stem and cauliflower-like structures, can be detected by real-time measurement of turbidity, since pyrophosphate ions are a byproduct of the reaction, which is visible as magnesium pyrophosphate in the reaction mixture $[106,130,131]$. The relation between the turbidity and the amount of DNA is linear [131]. A positive reaction is visible as a white precipitate and can be observed by the naked eye [107]. Another option is to use SYBR Green I as the DNA stain, with a detection limit of 210 copies $/ \mathrm{mL}$ according to Cai et al. [130,132]. Deguo et al. worked on the detection of Salmonella and have reported that the LAMP reaction is only effective when the template is pure. In fact, when there are inhibitors present, the sensitivity of PCR is higher [133].

Digital LAMP was conducted by Gansen et al., and they claimed that amplification in test tubes required less than $1 \mathrm{~h}$. This technique can be used to quantify absolute concentrations of DNA in a biological sample with sample volumes less than $2 \mu \mathrm{L}$ [117]. Luo et al. designed a microfluidic device for the multiplex real-time quantitative differentiation of bacteria by the use of LAMP. The chips contain eight isolated electrochemical chambers with a total volume of about $20 \mu \mathrm{L}$. The whole differentiation process takes about $45 \mathrm{~min}$, and the end of the reaction is electrochemically detected with a decreasing redox current. Furthermore, SYBR Green dye was added after the amplification for detection by the use of UV light [134].

A forensic DNA test with the use of the LAMP reaction has been developed by Watthanapanpituck et al. to determine if a sample is of human origin. The primers developed are human-specific and amplify the human cytochrome $b$. The product was analyzed with ethidium bromide (EtBr)-stained agarose gels and colorimetric detection with non-cross-linking gold nanoprobes. The test could identify human DNA from several biological samples, such as fresh blood, semen and saliva. The human samples showed a positive signal, whereas the samples from chimpanzee, orangutan, mouse, dog, cat and some other animals did not amplify [135].

\subsubsection{MDA}

MDA is also known as whole genome amplification (WGA) and is a strand displacement method. The method can be used to amplify circular DNA, as well as linear DNA and makes use of random hexamer primers and $\phi 29$ DNA polymerase. Samples with at least $1 \mathrm{ng}$ of DNA (in not more than $1 \mu \mathrm{L}$ ) are normally incubated overnight $(16-18 \mathrm{~h})$ at $30^{\circ} \mathrm{C}$ with a termination step at $65{ }^{\circ} \mathrm{C}$ for $10 \mathrm{~min}$, as suggested by the manufacturer $[108,136]$. However, Dean et al. observed a plateau reached after 4-6 h [108]. Furthermore, Kumar et al. could generate 4-7 $\mu \mathrm{g}$ of DNA from a single human cell within $4 \mathrm{~h}$ [137]. MDA shows a self-limiting reaction with a plateau when around $0.7-10.0 \mu \mathrm{g} / \mu \mathrm{L}$ is reached [121]. The processivity of $\phi 29$ is higher than $70 \mathrm{~kb}$, which is the highest known for any polymerase. This allows the replication of the whole genome with only one binding and priming event necessary. There is no need for unwinding proteins (such as helicase), since $\phi 29$ shows strand displacement activity. The DNA amplification with $\$ 29$ is a continuous process, which is exponential and completely isothermal $[108,138]$. Although not necessary, it is possible to denature the DNA by heating the template mixture at $95{ }^{\circ} \mathrm{C}$ for a few minutes, after which the polymerase needs to be 
added, as $\phi 29$ will be heat inactivated at temperatures of $65^{\circ} \mathrm{C}[108,136]$. In comparison to Taq DNA polymerase, $\phi 29$ shows an excellent proofreading activity and a lower misincorporation rate [138]. Twenty to $30 \mu \mathrm{g}$ of product can be generated from as few as 1-10 copies of DNA; the lysate does not have to be purified, and therefore, it is possible to carry out MDA from samples such as crude whole blood and tissue culture cells [108,136]. Despite the isothermal advantage, MDA has two main drawbacks: non-specificity due to the random primers (which can also lead to the synthesis of the DNA contamination or primer dimers) and uneven representation of the template due to amplification bias [121].

Although Asiello et al. do not describe the MDA reaction in detail in their article, they claim that microfluidic devices based on MDA could be useful in forensics and single cell sequencing [101]. Marcy et al. studied the amplification by MDA from a single cell, and they could obtain sufficient DNA for sequencing [121]. Ballantyne et al. showed that it is possible to use MDA to amplify genomic DNA from small amounts of template, $5 \mathrm{pg}-1 \mathrm{ng}$, for downstream STR multiplex genotyping. The amplification success is increased when a small amount is mixed with a second larger DNA sample. Therefore, the use of molecular crowders, additional DNA or polymers, such as PEG, increases the success rate of MDA, producing more detectable alleles in STR-genotyping [139]. The same group also investigated two different methods for WGA: the GenomiPhi and the GenomePlex kits. The two kits were tested on STR-genotyping of low copy number (LCN) and degraded DNA samples. They showed that by using WGA, the quality and quantity of DNA can be increased and that it has the potential to improve STR-typing from difficult samples in forensic casework. Both kits could amplify the LCN DNA, but only GenomiPhi showed an increase in profiling success. The profiling success from digested DNA was improved by both kits [140].

Although fast well-based and continuous-flow PCR chips are realized, with amplification times under $5 \mathrm{~min}$, these systems are not very suitable for forensic applications. In forensic casework, the samples are not as ideal as in the researched conditions, with pure DNA as input and very short amplicon lengths (under $100 \mathrm{bp}$ ). In order to reduce the amplification time, on-chip PCR in droplets and/or isothermal amplification techniques are promising alternatives, due to the many advantages, such as no interaction with the channel walls, increased mixing efficiency, shorter heat and mass transfer times (for droplet PCR) and/or no thermal cycling required (for isothermal amplification).

\section{Detection}

There are various methods for the detection of DNA, as already shown in Tables 1, 2 and 4. Absorbance detection is an option, but the majority of the techniques using on-chip are based on fluorescence detection, sometimes combined with CE. Three main principles result in the occurrence of fluorescence: an (intercalating) dye to stain the DNA, fluorescently-labeled deoxynucleotides (dNTPs) and the incorporation of a fluorescent dye into the amplicon with a labeled oligonucleotide primer. An advantage of dye-labeled primers is that they can be used in multiplex assays, such as STR analysis [4]. Intercalating dyes, such as SYBR Green and EvaGreen, are sequence independent. For specific detection, hydrolysis probes, such as TaqMan probes, or conformation probes (molecular beacons) can be used [5,55].

\subsection{Absorbance Detection}

To quantify dsDNA, the absorbance at $260 \mathrm{~nm}$ can be measured by UV-spectrophotometry, which is a fast and simple method [51]. The drawback of this technique is that such measurements are rather insensitive (below $5 \mathrm{ng} / \mu \mathrm{L}$, measurements are not accurate, which is a typical concentration of a forensic sample) and influenced by the contribution of nucleotides and single-stranded DNA or contaminants (such as proteins or phenol) [51,52,141]. Although the absorbance measurement can still be used as the indicative method, for forensic applications, fluorescence methods are used for the detection and quantification of DNA, such as nucleic acid stains and nucleic acid labels [51]. 
Another option to monitor DNA amplification with absorbance detection is by using $\mathrm{pH}$-sensitive dyes. When a deoxynucleotide triphosphate (nucleotide) is incorporated into the new DNA strand by the DNA polymerase in an amplification reaction, a hydrogen ion is released. This results in a drop of the $\mathrm{pH}$ of the amplification mixture. Tanner et al. used phenol red, cresol red, neutral red and $\mathrm{m}$-cresol purple to show the $\mathrm{pH}$ change within LAMP, which is visible by the human eye after $30 \mathrm{~min}$ of incubation at $65^{\circ} \mathrm{C}$. Furthermore, visual detection of PCR (1287-bp amplicon and 40 cycles) with phenol red and SDA with all of the above-mentioned dyes is possible [142]. Rodriquez-Manzano et al. used an unmodified camera phone to monitor the amplification of $\lambda$ DNA and hepatitis $C$ viral RNA with LAMP carried out on a chip. They used Eriochrome Black $\mathrm{T}$ to detect the color change going from purple to blue upon amplification by using the green/red ratiometric value [143].

\subsection{Fluorescence Detection}

\subsubsection{DNA Dyes}

A DNA dye stains all of the DNA present in a sample, and therefore, only one extinction and emission wavelength can be used. Differentiation between different amplicons is thus not possible, which is a drawback of this method. There are three main classes of nucleic acid stains: intercalating dyes (e.g., EtBr and PI), minor-groove binders (e.g., DAPI and Hoechst dyes) and other nucleic acid stains (e.g., acridine orange) [144].

In the past, EtBr and PI were often used, which belong to the group of classic intercalating dyes. However, the cyanine dyes are much more sensitive and far less mutagenic than a classic gel stain, such as EtBr [144]. An additional advantage is that most unsymmetrical cyanine dyes, such as SYBR Green and EvaGreen, have a low background fluorescence, a high binding affinity to DNA and a high fluorescent quantum yield [145].

Dyes, such as SYBR Green and EvaGreen, are already widely incorporated in on-chip analysis of DNA, as can be seen in Tables 1, 2 and 4 .

\subsubsection{Fluorescent dNTPs}

Fluorescently-labeled dNTPs will be incorporated in the DNA during the amplification reaction (usually PCR). This type of DNA detection is used in Sanger sequencing, but with the upcoming other (whole genome) next generation sequencing techniques, this is not widely used anymore [146,147].

\subsubsection{Fluorescent Primers}

To detect a complementary target sequence, a fluorescent-labeled primer or probe can be used. Fluorescent-labeled primers are more expensive than DNA dyes, but more than one color (dyes with different emission wavelengths) can be used. Therefore, amplicons can be separated by using different colors for different primers. Most forensic STR kits use four to five dyes in combination with CE detection and analysis [4].

Liu et al. used for their chip, the PowerPlex ${ }^{\circledR} 16$ System, a system that allows co-amplification and three-color detection of sixteen loci $[148,149]$. Other used kits on-chip, among others, are Profiler Plus ${ }^{\circledR}$ [47], the PowerPlex ${ }^{\circledR} 18$ Fast System [150], AmpFISTR ${ }^{\circledR}$ MiniFiler $^{\text {TM }}$ and AmpFISTR ${ }^{\circledR}$ Identifiler ${ }^{\circledR}$ amplification kits [48].

\subsection{Capillary Electrophoresis}

In order to generate an STR profile, separation and detection of the DNA fragments must take place. As Pascali et al. indicate in their review from 2011, an important field of interest within forensics is the development of microfluidic devices for CE in order to obtain an STR profile [151]. Mitnik et al. developed a glass chip for the detection of STR fragments by the use of electrophoresis in combination with laser-induced fluorescence. Within $20 \mathrm{~min}$, a single-base-pair resolution of $0.75-1$ can be observed for eight loci [152]. A CE micro-device for mini Y STR genotyping is developed by 
Chen et al. Although a high background of female DNA was present, they could perform the analysis with only $25 \mathrm{pg}$ of male DNA. The seven loci could be separated and detected in the $7 \mathrm{~cm}$-long separation channel by laser-induced confocal fluorescence microscopy [153]. Date-Chong et al. could obtain a full STR profile from a reference sample with their system (RapidHit). The software of the system had several built-in quality flags, which appear, e.g., in the case of an inconclusive homozygote allele, intra-locus imbalance or out of allelic/locus marker range. Of all of the reference buccal samples, $50 \%$ passed the two criteria of generating a full profile, without any quality flag that would require manual review/editing [154]. A micro-device with a 1.5-cm channel was used by Aboud et al. for the separation of seven loci (MP7 STR kit) within $80 \mathrm{~s}$ with a sizing precision of $\pm 0.21 \mathrm{bp}$ [155].

For on-chip analysis, DNA dyes, such as SYBR Green I or EvaGreen, are widely used. Detection by a fluorescent (intercalating) dye is simple and fast, but these dyes are non-specific, and multiplexing is not possible. For specific detection, fluorescent primers or probes are usually the method of choice. In order to obtain an STR-profile, CE needs to be combined with a fluorescent primer or probe, which makes chip design and detection more complicated. Integration of the detection step into a chip is not always easy, which is also reflected in Tables 1,2 and 4, by the amount of chips that make use of off-chip detection.

\section{Secure Storage}

Extracted DNA is usually stored at $-20^{\circ} \mathrm{C}$ or $-80^{\circ} \mathrm{C}$ [156]. The Netherlands Forensic Institute has a state-of-the-art integrated storage freezer from Hamilton for extracts at $-80{ }^{\circ} \mathrm{C}$ (up to 80 years), conforming to the legal terms of the Dutch law [157]. There is a need for secure storage at room temperature, since freezing of samples is costly and there is a serious risk of failure. Anhydrobiosis, whereby water is replaced by other compounds, such as trehalose, is forthcoming. Frippiat et al. showed that with commercially available kits, it is possible to store the DNA extracts for more than six months at room temperature and that the samples were preserved from degradation [156]. Furthermore, Lee et al. evaluated a commercially available storage medium that can be used at room temperature. They concluded that no significant difference could be seen between liquid frozen DNA samples and samples stored in the medium at room temperature. For low concentrations and long-term storage, the DNA recovery was even higher by using the storage medium, which makes it a promising method for the secure storage of forensic DNA samples [158].

Nevertheless, the secure storage has not yet been widely integrated in conventional DNA analysis techniques. By using chips, the sample stays in an enclosed environment, whereby the chain of custody is ensured and the risk of (cross-)contamination minimized. The developments of techniques for on-chip secure storage are of utmost importance for the forensic field and can create opportunities in comparison with conventional techniques. Integrated sample coding contributes to the chain of custody, and follow-up analysis of the DNA in a forensic laboratory can be carried out. It is possible to secure the end product of the analysis performed at the crime scene, as well as an untreated part of the sample (e.g., before the sample work-up) by dividing the input sample into a part that is directly analyzed and a part that is stored on-chip for further analysis in a forensic laboratory. Not much research has been performed yet on the secure storage on a chip of biological samples, although for forensics, it is really important to store the sample in a secure way.

\section{Chip Materials for DNA Analysis}

Most microfluidic chips are made of silicon or glass, although during the last decade, the use of plastic substrates (for instance PDMS or PMMA) has become very popular [159]. For forensic applications, chips are only for one-time use, thus disposable, and can therefore be made of an inexpensive material, as long as it fulfills all requirements. The selection of materials is not always straightforward, since the material itself can negatively affect the steps in the process of DNA analysis, such as PCR and detection. 
Glass is widely used because of the favorable optical (transparent) and electrical properties (insulating, which is useful for electrophoresis on-chip). In order to minimize the absorption of the PCR components on glass, the material must be coated or passivated [29,34].

Silicon is also widely used for chips due to its good thermal conductivity, which makes it suitable for the fast heating and cooling required in PCR cycling. However, because it is a semiconductor, it cannot withstand the high voltages required for CE. Furthermore, it is not transparent to the UV-VIS light needed for detection. Untreated silicon is known to inhibit the PCR reaction $[160,161]$. Cho et al. performed a small literature study and concluded that most static PCR chips are made from silicon. Furthermore, glass is used, but silicon is preferred due to its high thermal conductivity (although thermal isolation is necessary) [161].

Plastic devices involve fast fabrication (mostly based on molding) and are very suitable for SPE and CE on-chip [29,34]. The low costs make plastic chips suitable as disposables, which reduces maintenance and especially cross-contamination issues [67,162]. Plastic devices are attractive due to the bio-compatibility, but have a low thermal conductivity [161]. For continuous-flow devices, glass or plastic is more used, since a low thermal conductivity is desirable for the realization of different temperature zones in the chip [67]. Therefore, many microfluidic devices for biological fluid analysis are made from PDMS or PMMA $[18,19,39,88,163,164]$, although glass or silicon is also utilized $[31,58,65,152,165]$.

Many microfluidic devices for droplet generation or microfluidic DNA amplification are made of PDMS [166-170]. The benefit of using PDMS is the fact that the surface of the channel is hydrophobic. Aqueous droplets in oil are more easily formed in channels with a hydrophobic surface [171]. Next to that, PDMS is bio-compatible, transparent and easily moldable [172]. Due to its permeable nature, uncoated PDMS might show inhibition of the amplification reaction by adsorption or absorption of components in the amplification mix, especially the enzyme. This problem can be solved by coating of the PDMS with BSA [173]. To prevent evaporation, also parylene $\mathrm{C}$ can be used to coat the chip $[174,175]$. In case of water-in-oil systems, the template DNA present in the aqueous phase cannot adsorb to the walls of the chip due to the hydrophobic properties of the oil [176].

The material choice highly depends on the desired functionalities of the chip. Optical and electrical properties are important characteristics to take into account. The selected material should avoid absorption of components in the amplification mixture or inhibit the amplification reaction. An important aspect of chips for forensic applications is that they are disposable, to ensure no contamination can occur. Furthermore, production costs and material pricing are important factors.

\section{Chips with Integrated Functionality}

On the research level, several microfluidic devices (mostly continuous-flow) for DNA analysis with two or more steps, as depicted in Figure 1, integrated into one chip are reported. Table 5 shows various integrated chips and their characteristics. The applied methods for lysis, extraction and detection are given. The challenge is to combine all of the steps of the complete DNA analysis process, from sample input to analysis and secure storage of the sample. Nowadays, a few commercial systems are available, although their deployment is still limited. In the following subsections, various research chips, as well as some commercial chip-based systems are discussed in detail. 
Table 5. Overview of various integrated chips. SPE, solid phase extraction; AD, amperometric detector.

\begin{tabular}{|c|c|c|c|c|c|c|}
\hline Chip Material & Lysis & Extraction & Cycles* & Detection & Remarks & Year and Ref \\
\hline Glass & - & - & $\begin{array}{c}\text { PCR } \\
20(136 \mathrm{bp}, 10 \mathrm{~min})\end{array}$ & $\mathrm{CE}$ & $\begin{array}{l}280 \text { nL PCR chambers } \\
\text { Valve design }\end{array}$ & (2000) [177] \\
\hline PDMS/Glass & $\begin{array}{c}\text { Thermal } \\
2 \text { min @ } 95^{\circ} \mathrm{C}\end{array}$ & - & $\begin{array}{c}\text { PCR } \\
30(273 \mathrm{bp}, 27 \mathrm{~min})\end{array}$ & $\begin{array}{c}\mathrm{Gel}+\mathrm{EtBr} \\
\text { Off-chip detection }\end{array}$ & EOFpumping & (2005) [11] \\
\hline $\begin{array}{l}\text { PMMA + silicon } \\
\text { + PDMS/Glass }\end{array}$ & $\begin{array}{l}\text { Chemical } \\
\text { Guanidine lysis buffer }\end{array}$ & $\begin{array}{c}\text { SPE } \\
\text { Porous silicon }\end{array}$ & $\begin{array}{c}\text { PCR } \\
35 \text { (293 bp, } 50 \mathrm{~min})\end{array}$ & $\begin{array}{l}\text { SYBR Green } \\
\text { and Gel }\end{array}$ & $\begin{array}{l}\text { Region for cell separation } \\
\text { Blood sample }\end{array}$ & (2007) [178] \\
\hline Polycarbonate & $\begin{array}{l}\text { Chemical } \\
\text { Lysis buffer }\end{array}$ & $\begin{array}{c}\text { SPE } \\
\text { Silica membrane }\end{array}$ & $\begin{array}{c}\text { (RT-)PCR } \\
\text { 25-35 (Bacterial/viral, 28-130 min) }\end{array}$ & $\begin{array}{l}\text { Up-converting phosphor } \\
\text { reporter particles } \\
\text { Antibody-antigen }\end{array}$ & $\begin{array}{c}\text { Paraffin valves } \\
\text { Dried reagents in the chip }\end{array}$ & (2010) [149] \\
\hline $\begin{array}{l}\text { Borofloat } \\
\text { glass }\end{array}$ & - & $\begin{array}{c}\text { SPE } \\
\text { Silica beads }\end{array}$ & $\begin{array}{c}\text { PCR } \\
28(\text { STR, } 140 \mathrm{~min})\end{array}$ & - & $\begin{array}{l}\text { STR fragments } \\
\text { Off-chip detection }\end{array}$ & (2010) [47] \\
\hline $\begin{array}{l}\text { Borofloat } \\
\text { glass }\end{array}$ & - & $\begin{array}{c}\text { SPE } \\
\text { Silica beads }\end{array}$ & $\begin{array}{c}\text { PCR } \\
32(\mathrm{STR}, 60 \mathrm{~min})\end{array}$ & - & $\begin{array}{l}\text { STR fragments } \\
\text { Off-chip detection }\end{array}$ & (2011) [48] \\
\hline $\begin{aligned} & \text { Glass } \\
&+ \text { PDMS } \\
&\end{aligned}$ & - & $\begin{array}{c}\text { Beads } \\
\text { Magnetic }\end{array}$ & $\begin{array}{c}\text { PCR } \\
32(\mathrm{STR}, 40 \mathrm{~min}) \\
\end{array}$ & $\begin{array}{c}\mathrm{CE} \\
\text { Biotin label } \\
\end{array}$ & $\begin{array}{c}\text { STR fragments } \\
\text { Resistance temperature detector }\end{array}$ & (2011) [179] \\
\hline $\begin{aligned} & \text { Glass } \\
+ & \text { PDMS }\end{aligned}$ & $\begin{array}{l}\text { Electrochemical } \\
0-10 \text { V DC }\end{array}$ & - & $\begin{array}{c}\text { PCR } \\
25(100-595 \mathrm{bp},-)\end{array}$ & $\begin{array}{c}\text { CE-AD } \\
\text { and Gel + EtBr }\end{array}$ & $\begin{array}{l}\text { Amperometric detection } \\
\text { Combination of modules }\end{array}$ & (2012) [180] \\
\hline $\begin{array}{l}\text { PMMA } \\
+ \text { PDMS }\end{array}$ & $\begin{array}{l}\text { DNA liberation } \\
\text { Enzymatic }\end{array}$ & - & $\begin{array}{c}\text { PCR } \\
32(\mathrm{STR}, 26 \mathrm{~min})\end{array}$ & - & $\begin{array}{l}\text { STR fragments } \\
\text { IR heating }\end{array}$ & (2013) [181] \\
\hline PDMS/Glass & - & $\begin{array}{c}\text { Membrane } \\
\text { Aluminum oxide }\end{array}$ & $\begin{array}{c}\text { PCR } \\
60 \text { (Bacterial, } 101 \mathrm{~min})\end{array}$ & FAM probes & 2-step PCR & (2013) [182] \\
\hline $\begin{array}{l}\text { Cyclic olefin } \\
\text { polymer }\end{array}$ & - & - & $\begin{array}{c}\text { PCR } \\
27(\mathrm{STR}, 45 \mathrm{~min})\end{array}$ & $\begin{array}{l}\text { Electrophoretic } \\
\text { PowerPlex }\end{array}$ & $\begin{array}{c}\text { STR fragments } \\
\text { For reference samples }\end{array}$ & (2014) [150] \\
\hline
\end{tabular}

${ }^{*}$ Cycle time including initial denaturation and final extension, if used. If no amplification time were given, the total time of the PCR protocol was taken. 


\subsection{Research Chips}

A miniature analytical thermal cycling instrument (MATCI) has been developed by Northrup et al. By the use of silicon reaction chambers, several amplicons could be successfully amplified and detected in real-time with EtBr. The heaters are integrated in the system, and the whole PCR and detection setup fits into a briefcase [183].

Lee et al. have made a microfluidic device to carry out cell lysis and DNA amplification by combining an electroosmotic pump, an active micromixer and a temperature control system on-chip. The cells are thermally lysed and then moved to the PCR section by the use of an electroosmotic pump. The complete PCR is carried out within $27 \mathrm{~min}$ with a total sample volume of $15 \mu \mathrm{L}$ [11]. A module for lysis, PCR amplification and detection by CE are combined by Jha et al. They developed a glass chip for the genetic analysis of various cell types and $\lambda$ phage DNA, with amplicon sizes of 100-595 bp. The amplification time depends on the used flow rate. For a flow rate of $5 \mu \mathrm{L} / \mathrm{min}$, the retention time in each of the three zones is about $30 \mathrm{~s}$ (which makes a total amplification time of about $37.5 \mathrm{~min}$ ). The total time, from lysis till detection, is over $40 \mathrm{~min}$ with $22 \mathrm{~min}$ for cell lysis and 15-20 min to detect the amplicon with CE-AD (capillary electrophoresis with amperometric detector) [180].

Hopwood et al. have developed a microfluidic system for rapid forensic DNA analysis by means of which it is possible to obtain an STR profile from a suspect (or victim) within $4 \mathrm{~h}$. The chip combines DNA purification, PCR amplification and separation of the amplicons by CE in combination with laser-induced fluorescence (LIF) detection. As the input material, cell lysate is used from a buccal swab [38]. Over time, several improvements have been made to this MiDAS system (miniaturized integrated DNA analysis system). An upgrade is that not the lysate, but the swab head can be used as the input via the integrated swab sample lysis module. In this system, the complete process from lysis up to STR detection takes more than $2 \mathrm{~h}$ [184]. Furthermore, Bienvenue et al. designed a chip for forensic DNA analysis via PCR amplification of STR fragments. A conventional thermocycler is used for the amplification reaction on-chip with a volume of $1.2 \mu \mathrm{L}$. The cells were chemically lysed off-chip with proteinase $\mathrm{K}$ and fuanidine and introduced into the micro-device for the purification by means of an SPE channel filled with silica beads. Detection and analysis were also done off-chip, with conventional CE [47]. Within 42-45 min, the PCR product could be obtained from a sample by the use of a PMMA chip for DNA extraction and PCR amplification. A part of a swab can be loaded into the device, after which infrared heating is used to activate the enzyme-based reagents for the DNA liberation. The micro-device can be used for STR-typing, including the amelogenin gene (sex typing), although only partial profiles were obtained (21 of 26 alleles expected) [181].

Most micro-devices are designed for only one of the consecutive steps for forensic DNA analysis. In the last couple of years, several research groups combined two or three of the steps into one chip. Some of the chips do not contain a module for lysis, although off-chip lysis requires an extra transfer step, which increases the risk of contamination. Besides that, often only a fraction of the whole sample is loaded on the chip, and therefore, the PCR might not be successful, as indicated by Lounsbury et al. [181]. Liu et al. have developed a device that combines the steps of PCR amplification and CE [185]. A few years later, they also combined this with purification of the sample and post-PCR cleanup [148]. A nine-plex STR profile from $2.5 \mathrm{ng}$ input standard DNA in about $3 \mathrm{~h}$ was acquired with this chip, which is depicted in Figure 6. The step of cell lysis was carried out off-chip [179]. 


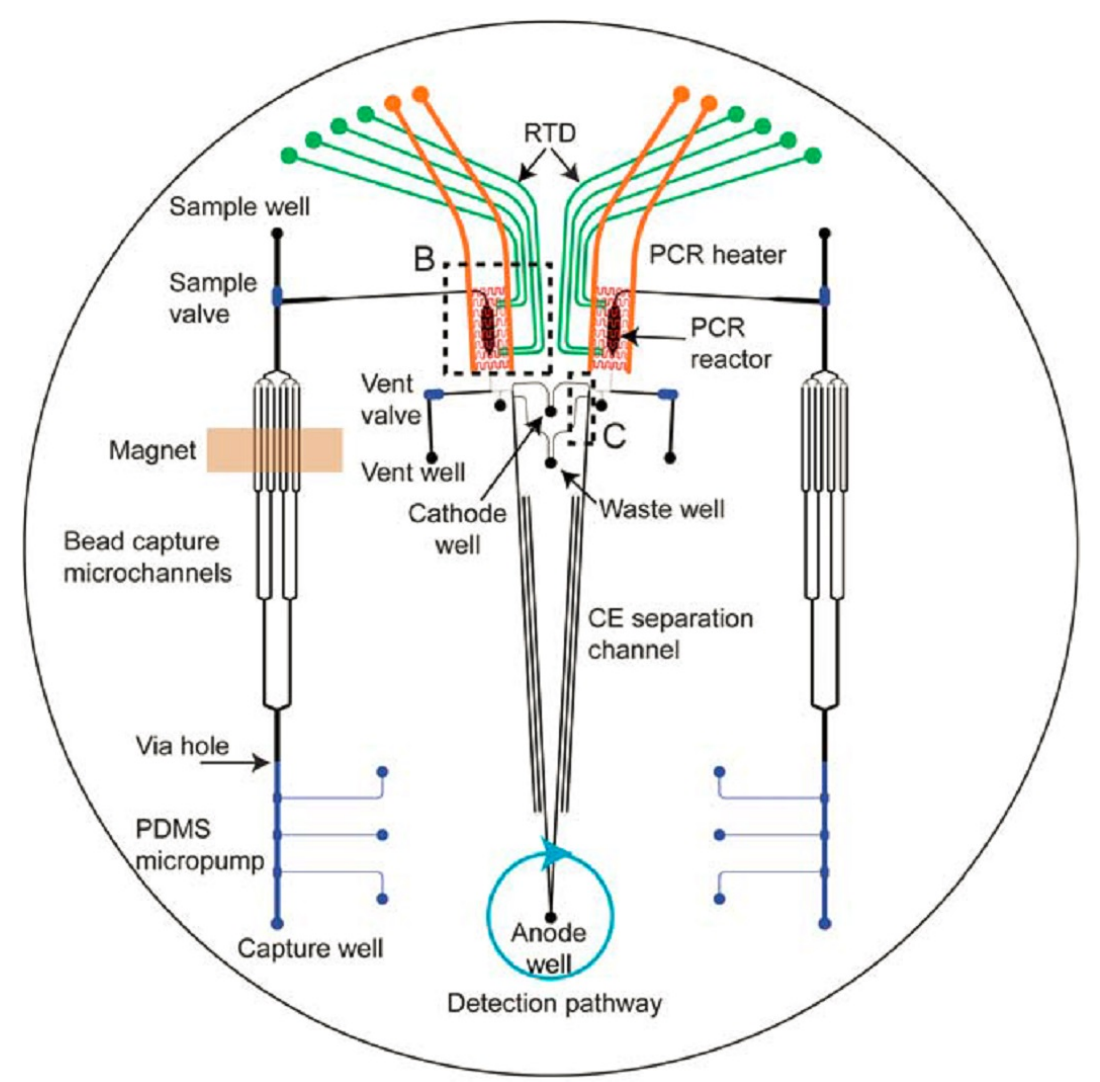

Figure 6. Design of the DNA analysis chip of Liu et al. with sections for DNA purification, PCR and CE separation (reproduced from [179] with permission of The Royal Society of Chemistry).

Xu et al. have developed a PCR chip for a forensic test. With the disposable device, short and long DNA fragments could be amplified, as well as STRs. Norland Optical Adhesive 81 (NOA 81) was used as the chip material, which does not absorb DNA polymerase, and therefore, coating (with, e.g., bovine serum albumin) is not required. However, the STR analysis was carried out off-chip with a conventional CE-system [186].

In 2015, Romsos et al. discussed several rapid PCR methods for STR analysis in their review. The PCR protocol has been speeded up by using faster polymerases and by performing direct PCR (i.e., skipping the extraction step). With these adjustments, the cycling time can be brought back to about $45 \mathrm{~min}$ (in comparison with 2-3 h for conventional protocols). By miniaturization, the PCR volume is reduced, and the total cycling time can be further brought back. However, most of the devices are specifically designed for (fast) PCR, but do not integrate other steps in the process of DNA analysis [187]. Only a few micro-devices combine the steps from cell lysis up to detection and analysis of the sample, such as the chip of Chen et al. [149]. Lounsbury et al. reported a chip where (part) of a swab can be introduced as input [181]. Integration of all of the consecutive steps in the process of forensic DNA analysis, as described in Figure 1, is still an enormous challenge. However, since for forensic investigations, analysis time and contamination are important issues, the final goal will be to integrate all of these steps in one (micro-)device, which can be used directly at the crime scene.

\subsection{Commercial Chip-Based Systems}

A few companies have developed chip-based systems for forensic DNA analysis, although these commercial systems are still expensive [188].

ParaDNA from LGC Forensics is a system, based on HyBeacons ${ }^{\circledR}$ technology, that can analyze a crime scene sample within $75 \mathrm{~min}$. The beacons are made of short DNA sequences with one or more fluorescent dyes, which will emit when the complementary DNA is attached to the beacon. 
ParaDNA screens two STRs and the sex marker amelogenin, and four tests can be run simultaneously. The sample collector takes a small portion of the crime scene sample [189]. Of the 381 DNA samples tested by Ball et al. only $0.15 \%$ were discordant with the AmpFISTR ${ }^{\circledR}$ SGM Plus ${ }^{\circledR}$ profile. Dropout by the ParaDNA Intelligence Test was seen for samples with a heterozygote imbalance or due to high stutter [190]. Blackman et al. showed that more then $65 \%$ of the samples gave full ParaDNA ${ }^{\circledR}$ profiles (12 alleles) at $4 \mathrm{ng}$ or more DNA (which corresponds to $1 \mathrm{ng}$ per well). For more then $80 \%$ of the samples, a "usable" (seven or more alleles detected) profile could be generated with $250 \mathrm{pg}$ of DNA [191].

The RapidHIT ${ }^{\mathrm{TM}}$, a machine of $81.5 \mathrm{~kg}$, can create a full STR profile, based on PCR and CE, within 90 min from buccal swabs and other human samples. This system, from Integen $X^{\circledR}$, contains a cartridge in which five samples (present on a swab) can be run at the same time. A second cartridge contains a positive and a negative control, as well as an allelic ladder [54,192]. Hennessy et al. studied the sensitivity, accuracy and genotype concordance of the RapidHIT system. Upon the addition of DNA to the vials, full profiles were obtained till $500 \mathrm{pg}$ and down to $25 \mathrm{pg} 65 \%$ of the alleles were detected. With DNA added to swabs, a sensitivity of $100 \mathrm{ng}$ was obtained and $52 \%$ of the alleles were detected with an amount of $5 \mathrm{ng}$ added to the swab. All standards tested were in 100\% concordance with the certified reference profiles, and for 150 buccal swab samples, a 100\% genotype concordance was obtained. The 13 Combined DNA Index System (CODIS) core loci were present on $94.7 \%$ of the samples [193]. In the study of Jovanovich et al., a sensitivity level of $176 \mathrm{ng}$ saliva DNA was obtained (concordant full profiles), and still, $57 \%$ of the alleles could be detected with $16 \mathrm{ng}$ of DNA on a swab. For the positive controls (37 samples), a 100\% success rate was obtained. Two-hundred nineteen of the 250 buccal samples were fully in concordance with the PowerPlex 16 profile on the first pass [54]. At first, the RapidHit was designed for reference samples, such as buccal swabs. Nowadays, a wider variety of samples, such as bloodstains and saliva samples, can be used as input [194]. Verheij et al. showed that DNA profiling is possible when buccal swabs are used, and with the updated system, also saliva, semen, skin and hair samples can be utilized. However, for traces other than buccal swabs, profiling success rates are variable, and with lower input samples, profiling artifacts were present. In their study, blood presumably contained inhibitors, since no profile could be obtained [195].

NetBio has developed a similar system, which uses a BioChipSet ${ }^{\mathrm{TM}}$ cassette, to perform STR analysis of 15 loci within $84 \mathrm{~min}$. Five buccal swabs can be analyzed at the same time, and the DNA is purified by guanidinium-based lysis and silica binding. The PCR reaction mix is lyophilized, and the profile is generated by electrophoresis. Of the 100 buccal samples tested, 85 generated a full CODIS profile. Five samples resulted in a partial profile, and from ten samples, no profile could be generated. Allelic concordance was greater than $99.95 \%$ (including a spike that was designated as an allele). The failures are caused by blocked channels, resulting in no amplification or electrophoresis of the sample [53].

Furthermore, NEC developed a "portable" DNA analyzer, which weighs $32 \mathrm{~kg}$, and the company claims that it can perform full analysis (nine loci) in only $25 \mathrm{~min}$ [196]. However, the entire process, from input to output, takes up to $50 \mathrm{~min}$, with $5 \mathrm{~min}$ for DNA extraction, $40 \mathrm{~min}$ for PCR amplification and $5 \mathrm{~min}$ for CE. Blood samples or buccal swabs can be used as input [197].

Although the chips developed at the research level integrate several steps in the process of DNA analysis in a truly microfluidic manner in a single device, the same level of integration is usually not reached for other components in the system. For example, off-chip electronic circuitry for temperature control or a microscope with a laser setup for detection are required. Therefore, these microfluidic devices cannot yet be operated outside a laboratory environment. In contrast, the commercial systems can be brought to the crime scene, although they are not really portable, considering their weight. Most importantly, however, forensic investigators have limited time on a crime scene and do not always have the opportunity to carry out an analysis that takes up to 75-90 min. 
For most commercial systems, the first validation studies are reported in terms of sensitivity, accuracy and genotype concordance and, sometimes, also for robustness (e.g., the use of degraded samples or the presence of inhibitors). In contrast, in the case of research chips, little to nothing is published about the performances in terms of allelic drop-in or drop-out, stutter, background signal or preferential amplification in association with small volumes (and thereby, low quantities of input DNA).

\section{Outlook}

In the last decade, significant progress has been made in the analysis of biological fluids in micro-devices. Single task chips are developed for the purification of genetic material, PCR amplification and STR analysis. Most of the devices are made for only one of the steps of the process of DNA analysis, and only a few have combined several steps in one chip. Besides that, devices that are designed for several steps are often not tested with real forensic samples.

The majority of the microfluidic devices uses a biological sample in a solution or the lysate/pure DNA as input material. The commercially available machines require swabs as the input; nevertheless, integration of trace sampling (e.g., by swabs) on-chip remains difficult and is therefore not yet realized at the research level, thereby becoming one of the technological challenges of DNA analysis on-chip. More research is needed concerning swabbing and sampling techniques that are designed and optimized to be interfaced with chip-based DNA analysis. Various conventional lysis methods are translated to on-chip applications. To make this technique more suitable for forensic samples, single cell lysis might be the way to go. The sample work-up step on-chip can be performed by $(\mu) \operatorname{SPE}$ or magnetic beads. Crime scene samples often contain low amounts of DNA, and therefore, it is a challenge to obtain as much DNA as possible after the sample work-up upon which amplification can be carried out. To speed up the analysis and improve the limit of detection, amplification can be performed in water-in-oil droplets in microchannels; each droplet functions as an independent reactor with a volume of pico- to nano-liters. To further reduce the analysis time, isothermal amplification is worth investigating. Therewith, instead of cooling and heating rates, as in conventional PCR, the enzyme reaction rate becomes the limiting factor. The (STR) analysis of the DNA fragments is usually performed by a combination of CE separation and fluorescence detection, which is, however, not always performed on-chip. A fluorescent dye that binds to dsDNA is an inexpensive and simple method for the detection step. In case specificity is required, more costly and complex primers or probes can be used. Secure storage of the sample, to minimize the chance of contamination and to ensure the chain of custody, is not yet realized with conventional techniques, but is a big opportunity for on-chip DNA analysis.

By the use of micro-devices, forensic DNA analysis (e.g., STR profiling) can become much faster and performed at the crime scene. However, at the moment, chips cannot be used directly at a crime scene. The majority of the devices still relies on external (non-portable) equipment. The input of most chips is lysate or already purified genomic material. Some commercial systems use buccal swabs as the input, but are not yet validated for evidence samples from a crime scene ("dirty" samples). Impressive on-chip developments have taken place; nevertheless, there is still no portable device containing all of the required steps available for fast analysis (within about $30 \mathrm{~min}$ for a full STR profile) of real "dirty" samples directly at the crime scene. It would also be ideal to have a multi-compartment chip for additional laboratory analyses and the storage of the sample (extract).

The most progress, considering STR profiling, has been made by the discussed commercial systems. Although the developed apparatuses are relatively heavy and therefore not applicable for portable use at the crime scene, they could provide valuable information upon use at a police station. Obtaining a full profile within even less time than possible at the moment is still a great desire of forensic scientists, but speed is not the only challenge within DNA analysis. There is also a desire to obtain a profile from trace samples, which contain a low amount of DNA (less than 100 pg), or degraded 
samples. Additional challenges with trace DNA are mixed DNA profiles and contamination [50]. These issues have not yet been incorporated within forensic DNA analysis on-chip.

The latest developments concerning DNA analysis on-chip focus on STR profiling. These trends might also contribute to developments within other biological trace research, such as Y-chromosomal profiling, mt-chromosomal profiling, RNA cell typing and phenotype profiling. One of the challenges of chip-technology is to develop platforms that enable other DNA or RNA analysis techniques.

Before micro-devices can truly be applied at a crime scene, some jurisdictive hurdles need to be overcome, as well. Amongst other aspects, the following issues need to be considered: the regulations concerning a forensic expert for the interpretation of DNA profiles and the (Dutch) law states that forensic DNA investigations can only be conducted by an accredited laboratory, the conditions for the uptake of a profile in the DNA databank, the right of contra investigation and the retention period of DNA (extracts). It is unclear at this point whether such regulations will hamper or stimulate the introduction of lab-on-a-chip devices in forensics or whether new regulations need to be established, in order to fully exploit the possibilities offered by micro-devices.

Acknowledgments: The authors would like to thank Dyonne Nijhuis for providing the SEM pictures of the swabs.

Conflicts of Interest: The authors declare no conflict of interest.

\section{References}

1. Mapes, A.A.; Kloosterman, A.D.; Poot, C.J. DNA in the criminal justice system: The DNA success story in perspective. J. Forensic Sci. 2015, 60, 851-856.

2. Van Asten, A.C. On the added value of forensic science and grand innovation challenges for the forensic community. Sci. Justice 2014, 54, 170-179.

3. Kloosterman, A.; Mapes, A.; Geradts, Z.; van Eijk, E.; Koper, C.; van den Berg, J.; Verheij, S.; van der Steen, M.; van Asten, A. The interface between forensic science and technology: How technology could cause a paradigm shift in the role of forensic institutes in the criminal justice system. Philos. Trans. B 2015, 370, doi:10.1098/rstb.2014.0264.

4. Butler, J.M. Forensic DNA Typing; Elsevier Academic Press: Cambridge, MA, USA; 2005.

5. Wu, J.; Kodzius, W.; Cao, R.; Wen, W. Extraction, amplification and detection of DNA in microfluidic chip-based assays. Microchim. Acta 2013, 181, 1611-1631.

6. Reinholt, S.J.; Baeumner, A.J. Microfluidic isolation of nucleic acids. Angew. Chem. Int. Ed. 2014, 53, 13988-14001.

7. Reedy, C.R.; Price, C.W.; Sniegowski, J.; Ferrance, J.P.; BegleyM.; Landers, J.P. Solid phase extraction of DNA from biological samples in a post-based, high surface area poly (methyl methacrylate)(PMMA) micro-device. Lab Chip 2011, 11, 1561-1700.

8. Kim, J.; Johnson, M.L.; Hill, P.; Gale, B.K. Microfluidic sample preparation: Cell lysis and nucleic acid purification. Integr. Biol. 2009, 1, 574-586.

9. Le Gac, S.; van den Berg, A. Cell Capture and Lysis on a Chip. In Unravelling Single Cell Genomics: Micro and Nanotools; Royal Society of Chemistry: Enschede, The Netherlands, 2010; Chapter 12.

10. Waters, L.C.; Jacobson, S.C.; Kroutchinina, N.; Khandurina, J.; Foote, R.S.; Ramsey, J.M. Microchip device for cell lysis, multiplex PCR amplification, and electrophoretic sizing. Anal. Chem. 1998, 70, 158-162.

11. Lee, C.-Y.; Lee, G.-B.; Lin, J.-L.; Huang, F.-C.; Liao, C.-S. Integrated microfluidic systems for cell lysis, mixing/pumping and DNA amplification. J. Micromech. Microeng. 2005, 15, 1215-1223.

12. Wiederkehr, R.S.; Jones, B.; Peeters, S.; Stakenborg, T.; Ibrahim, O.; Fiorini, P.; Tanaka, H.;Yamashita, I.; Matsuno, T.; Lagae, L. On-chip multiplex for amplification directly from whole blood. In Proceedings of the 17th International Conference on Miniaturized Systems for Chemistry and Life Sciences-MicroTAS, Freiburg, Germany, 27-31 October 2013; pp. 1776-1778.

13. Tsougeni, K.; Papadakis, G.; Gianneli, M.; Grammoustianou, A.; Constantoudis, V.; Dupuy, B.; Petrou, P.S.; Kakabakos, S.E.; Tserepi, A.; Gizeli, E.; et al. Plasma nanotextured polymeric lab-on-a-chip for highly efficient bacteria capture and lysis. Lab Chip 2016, 16, 120-131.

14. Lu, H.; Schmidt, M.A.; Jensen, K.F. A microfluidic electroporation device for cell lysis. Lab Chip 2005, 5, 23-29. 
15. Jen, C.-P.; Hsiao, J.-H.; Maslov, N.A. Single-cell chemical lysis on microfluidic chips with arrays of micro wells. Sensors 2011, 12, 347-358.

16. Fox, M.B.; Esveld, D.C.; Valero, A.; Luttge, R.; Mastwijk, H.C.; Bartels, P.V.; van Den Berg, A.; Boom, R.M. Electroporation of cells in microfluidic devices: A review. Anal. Bioanal. Chem. 2006, 385, 474-485.

17. Jiang, F.; Chen, J.N.; Yu, J. Design and application of a microfluidic cell lysis microelectrode chip. Instrum. Sci. Technol. 2015, 44, 223-232.

18. Di Carlo, D.; Ionescu-Zanetti, C.; Zhang, Y.; Hung, P.; Lee, L.P. On-chip cell lysis by local hydroxide generation. Lab Chip 2004, 5, 171-178.

19. Nevill, J.T.; Cooper, R.; Dueck, M.; Breslauer, D.N.; Lee, L.P. Integrated microfluidic cell culture and lysis on a chip. Lab Chip 2007, 7, 1689-1695.

20. Lee, H.J.; Kim, J.-H.; Lim, H.K.; Cho, E.C.; Huh, N.; Ko, C.; Park, J.C.; Choi, J.W.; Lee, S.S. Electrochemical cell lysis device for DNA extraction. Lab Chip 2010, 10, 626-633.

21. Di Carlo, D.; Jeong, K.H.; Lee, L.P. Reagentless mechanical cell lysis by nanoscale barbs in microchannels for sample preparation. Lab Chip 2003, 3, 287-291.

22. Lin, Y.-H.; Lee, G.-B. An optically induced cell lysis device using dielectrophoresis. Appl. Phys. Lett. 2009, 94, 033901.

23. Huang, S.-H.; Hung, L.-Y.; Lee, G.-B. Continuous nucleus extraction by optically-induced cell lysis on a batch-type microfluidic platform. Lab Chip 2016, 16, 1447-1456.

24. Shahini, M. Development of Cell Lysis Techniques in Lab on a Chip. Ph.D. Thesis, University of Waterloo, Waterloo, ON, Canada, 2013.

25. Brown, R.B.; Audet, J. Current techniques for single-cell lysis. J. R. Soc. Interface 2008, 5 (Suppl. 2), S131-S138.

26. Valero, A. Single Cell Electroporation on Chip. Ph.D. Thesis, University of Twente, Enschede, The Netherlands, October 2006.

27. Valero, A.; Post, J.N.; van Nieuwkasteele, J.W.; Ter Braak, P.M.; Kruijer, W.; van Den Berg, A. Gene transfer and protein dynamics in stem cells using single cell electroporation in a microfluidic device. Lab Chip 2008, 8, 62-67.

28. Shahini, M.; van Wijngaarden, F.; Yeow, J.T.W. Fabrication of electro-microfluidic channel for single cell electroporation. Biomed. Microdev. 2013, 15, 759-766.

29. Price, C.W.; Leslie, D.C.; Landers, J.P. Nucleic acid extraction techniques and application to the microchip. Lab Chip 2009, 9, 2484-2494.

30. Tian, H.; Hühmer, A.F.R.; Landers, J.P. Evaluation of silica resins for direct and efficient extraction of DNA from complex biological matrices in a miniaturized format. Anal. Biochem. 2000, 283, 175-191.

31. Hagan, K.A.; Bienvenue, J.M.; Moskaluk, C.A.; Landers, J.P. Microchip-based solid-phase purification of RNA from biological samples. Anal. Chem. 2008, 80, 8453-8460.

32. Wolfe, K.A.; Breadmore, M.C.; Ferrance, J.P.; Power, M.E.; Conroy, J.F.; Norris, P.M.; Landers, J.P. Toward a microchip-based solid-phase extraction method for isolation of nucleic acids. Electrophoresis 2002, 23, 727-733.

33. Breadmore, M.C.; Wolfe, K.A.; Arcibal, I.G.; Leung, W.K.; Dickson, D.; Giordano, B.C.; Mary, E.; Ferrance, J.P.; Feldman, S.H.; Norris, P.M.; et al Microchip-based purification of DNA from biological samples. Anal. Chem. 2003, 75, 1880-1886.

34. Duarte, G.R.M.; Price, C.W.; Augustine, B.H.; Carrilho, E.; Landers, J. Dynamic solid phase DNA extraction and PCR amplification in polyester-toner (PeT) based microchip. Anal. Chem. 2011, 83, 5182-5189.

35. Zhang, X.; Wu, X.; Peng, R.; Li, D. Electromagnetically controlled microfluidic chip for DNA extraction. Measurement 2015, 75, 23-28.

36. Barbaro, A.; Cormaci, P. Validation of DNA typing from skeletal remains using the Invitrogen Charge Switch ${ }^{\circledR}$ Forensic DNA Purification Kit. Forensic Sci. Int. Genet. Suppl. Ser. 2008, 1, 398-400.

37. Invitrogen. ChargeSwitch ${ }^{\circledR}$ PCR Clean-Up Kit, 2006. Available online: http://tools.invitrogen.com/ content/sfs/manuals/chargeswitch_PCR_man.pdf (accessed on 12 February 2016).

38. Hopwood, A.J.; Hurth, C.; Yang, J.; Cai, Z.; Moran, N.; Lee-Edghill, J.G.; Nordquist, A.; Lenigk, R.; Estes, M.D.; Haley, J.P.; et al. Integrated microfluidic system for rapid forensic DNA analysis: Sample collection to DNA profile. Anal. Chem. 2010, 82, 6991-6999.

39. Lien, K.Y.; Lee, W.C.; Lei, H.Y.; Lee, G.B. Integrated reverse transcription polymerase chain reaction systems for virus detection. Biosens. Bioelectron. 2007, 22, 1739-1748. 
40. Gu, S.Q.; Zhang, Y.X.; Zhu, Y.; Du, W.; Yao, B.; Fang, Q. Multifunctional picoliter droplet manipulation platform and its application in single cell analysis. Anal. Chem. 2011, 83, 7570-7576.

41. Yang, J.; Brooks, C.; Estes, M.D.; Hurth, C.M.; Zenhausern, F. An integratable microfluidic cartridge for forensic swab samples lysis. Forensic Sci. Int. Genet. 2014, 8, 147-158.

42. Bienvenue, J.M.; Duncalf, N.; Marchiarullo, D.; Ferrance, J.P.; Landers, J.P. Microchip-based cell lysis and DNA extraction from sperm cells for application to forensic analysis. J. Forensic Sci. 2006, 51, 266-273.

43. Voorhees Norris, J.; Evander, M.; Horsman-Hall, K.M.; Nilsson, J.; Laurell, T.; Landers, J.P. Acoustic differential extraction for forensic analysis of sexual assault evidence. Anal. Chem. 2009, 81, 6089-6095.

44. Horsman, K.M.; Bienvenue, J.M.; Blasier, K.R.; Landers, J.P. Forensic DNA analysis on microfluidic devices: A review. J. Forensic Sci. 2007, 52, 784-799.

45. Belgrader, P.I.; Yuan, B. Sonication to Selectively Lyse Different Cell Types. U.S. Patent 7,785,869, 31 August 2010.

46. Horsman, K.M.; Barker, S.L.R.; Ferrance, J.P.; Forrest, K.A.; Koen, K.A.; Landers, J.P. Separation of sperm and epithelial cells in a microfabricated device: Potential application to forensic analysis of sexual assault evidence. Anal. Chem. 2005, 77, 742-749.

47. Bienvenue, J.M.; Legendre, L.A.; Ferrance, J.P.; Landers, J.P. An integrated microfluidic device for DNA purification and PCR amplification of STR fragments. Forensic Sci. Int. Genet. 2010, 4, 178-186.

48. Hagan, K.A.; Reedy, C.R.; Bienvenue, J.M.; Dewald, A.H.; Landers, J.P. A valveless microfluidic device for integrated solid phase extraction and polymerase chain reaction for short tandem repeat (STR) analysis. Analyst 2011, 136, 1928-1937.

49. Meulenbroek, A.J.; Kloosterman, A.D. DNA-onderzoek van minimale biologische sporen; gevoelige problematiek. Analyse 2009, 64, 108-120.

50. Van Oorschot, R.A.; Ballantyne, K.N.; Mitchell, R.J. Forensic trace DNA: A review. Investig. Genet. 2010, 1, doi:10.1186/2041-2223-1-14.

51. Nicklas, J.A; Buel, E. Quantification of DNA in forensic samples. Anal. Bioanal. Chem. 2003, 376, $1160-1167$.

52. Lee, S.B.; McCord, B.; Buel, E. Advances in forensic DNA quantification: A review. Electrophoresis 2014, 35, 3044-3052.

53. Tan, E.; Turingan, R.S.; Hogan, C.; Vasantgadkar, S.; Palombo, L.; Schumm, J.W.; Selden, R.F. Fully integrated, fully automated generation of short tandem repeat profiles. Investig. Genet. 2013, 4, dio:10.1186/2041-2223-4-16.

54. Jovanovich, S.; Bogdan, G.; Belcinski, R.; Buscaino, J.; Burgi, D.; Butts, E.L.R.; Chear, K.; Ciopyk, B.; Eberhart, D.; El-Sissi, O.; et al. Developmental validation of a fully integrated sample-to-profile rapid human identification system for processing single-source reference buccal samples. Forensic Sci. Int. Genet. 2015, 16, 181-194.

55. Auroux, P.-A.; Koc, Y.; deMello, A.; Manz, A.; Day, P.J.R. Miniaturised nucleic acid analysis. Lab Chip 2004, 4 , 534-546.

56. El-Ali, J.; Perch-Nielsen, I.R.; Poulsen, C.R.; Bang, D.D.; Telleman, P.; Wolff, A. Simulation and experimental validation of a SU-8 based PCR thermocycler chip with integrated heaters and temperature sensor. Sens. Actuators A Phys. 2004, 110, 3-10.

57. Zhang, Y.; Ozdemir, P. Microfluidic DNA amplification: A review. Anal. Chim. Acta 2009, 638, 115-125.

58. Obeid, P.J.; Christopoulos, T.K.; Crabtree, H.J.; Backhouse, C.J. Microfabricated device for DNA and RNA amplification by continuous-flow polymerase chain reaction and reverse transcription-polymerase chain reaction with cycle number selection. Anal. Chem. 2003, 75, 288-295.

59. West, J.; Karamata, B.; Lillis, B.; Gleeson, J.P.; Alderman, J.; Collins, J.K.; Lane, W.; Mathewson, A.; Berney, H. Application of magnetohydrodynamic actuation to continuous flow chemistry. Lab Chip 2002, 2, 224-230.

60. Frey, O.; Bonneick, S.; Hierlemann, A.; Lichtenberg, J. Autonomous microfluidic multi-channel chip for real-time PCR with integrated liquid handling. Biomed. Microdev. 2007, 9, 711-718.

61. Liu, H.B.; Ramalingam, N.; Jiang, Y.; Dai, C.C.; Hui, K.M.; Gong, H.Q. Rapid distribution of a liquid column into a matrix of nanoliter wells for parallel real-time quantitative PCR. Sens. Actuators B Chem. 2009, 135, 671-677.

62. Zhang, Y.; Zhu, Y.; Yao, B.; Fang, Q. Nanolitre droplet array for real time reverse transcription polymerase chain reaction. Lab Chip 2011, 11, 1545-1549. 
63. Liu, Y.; Li, C.; Li, Z.; Chan, S.D.; Eto, D.; Wu, W.; Zhang, J.P.; Chien, R.-L.; Wada, H.G.; Greenstein, M.; et al. On-chip quantitative-PCR using integrated real-time detection by capillary electrophoresis. Electrophoresis 2016, 37, 545-552.

64. Kopp, M.U.; Mello, A.J.; Manz, A. Chemical amplification: Continuous-flow PCR on a chip. Science 1998, 280, 1046-1048.

65. Obeid, P.J.; Christopoulos, T.K. Continuous-flow DNA and RNA amplification chip combined with laser-induced fluorescence detection. Anal. Chim. Acta 2003, 494, 1-9.

66. Qi, H.; Wang, X.; Chen, T.; Ma, X.; Zuo, T. Fabrication and characterization of a polymethyl methacrylate continuous-flow PCR microfluidic chip using $\mathrm{CO}_{2}$ laser ablation. Microsyst. Technol. 2009, 15, 1027-1030.

67. Moschou, D.; Vourdas, N.; Kokkoris, G.; Papadakis, G.; Parthenios, J.; Chatzandroulis, S.; Tserepi, A. All-plastic, low-power, disposable, continuous-flow PCR chip with integrated microheaters for rapid DNA amplification. Sens. Actuators B Chem. 2014, 199, 470-478.

68. Hatch, A.C.; Ray, T.; Lintecum, K.; Youngbull, C. Continuous flow real-time PCR device using multi-channel fluorescence excitation and detection. Lab Chip 2014, 14, 562-568.

69. Sadler, D.J.; Changrani, R.; Roberts, P.; Chou, C.F.; Zenhausern, F. Thermal management of BioMEMS: Temperature control for ceramic-based PCR and DNA detection devices. IEEE Trans. Compon. Packag. Technol. 2003, 26, 309-316.

70. Chen, Z.; Qian, S.; Abrams, W.R.; Malamud, D.; Bau, H.H. Thermosiphon-based PCR reactor: Experiment and modeling. Anal. Chem. 2004, 76, 3707-3715.

71. Bu, M.; Melvin, T.; Ensell, G.; Wilkinson, J.S.; Evans, A.G.R. Design and theoretical evaluation of a novel microfluidic device to be used for PCR. J. Micromech. Microeng. 2003, 13, S125-S130.

72. Wang, W.; Li, Z.-X.; Luo, R.; Lü, S.-H.; Xu, A.-D.; Yang, Y.-J. Droplet-based micro oscillating-flow PCR chip. J. Micromech. Microeng. 2005, 15, 1369.

73. Nie, J.; Zhao, Y.; Peng, N. Multichannel oscillatory-flow PCR micro-fluidic chip with controllable temperature gradient. Microsyst. Technol. 2015, 21, 41-48.

74. Giordano, B.C.; Ferrance, J.; Swedberg, S.; Hühmer, A.F.R.; Landers, J.P. Polymerase chain reaction in polymeric microchips: DNA amplification in less than 240 seconds. Anal. Biochem. 2001, 291, 124-132.

75. Neuzil, P.; Zhang, C.; Pipper, J.; Oh, S.; Zhuo, L. Ultra fast miniaturized real-time PCR: 40 cycles in less than six minutes. Nucleic Acids Res. 2006, 34, e77.

76. Neuzil, P.; Pipper, J.; Hsieh, T.M. Disposable real-time microPCR device: Lab-on-a-chip at a low cost. Mol. BioSyst. 2006, 2, 292-298.

77. Fuchiwaki, Y.; Nagai, H.; Saito, M.; Tamiya, E. Ultra-rapid flow-through polymerase chain reaction microfluidics using vapor pressure. Biosens. Bioelectron. 2011, 27, 88-94.

78. Son, J.H.; Cho, B.; Hong, S.; Lee, S.H.; Hoxha, O.; Haack, A.J.; Lee, L.P. Ultrafast photonic PCR. Light Sci. Appl. 2015, 4, e280.

79. Son, J.H.; Hong, S.; Haack, A.J.; Gustafson, L.; Song, M.; Hoxha, O.; Lee, L.P. Rapid optical cavity PCR. Adv. Healthc. Mater. 2016, 5, 167-174.

80. Gu, H.; Duits, M.H.G.; Mugele, F. Droplets formation and merging in two-phase flow microfluidics. Int. J. Mol. Sci. 2011, 12, 2572-2597.

81. Baroud, C.N.; Gallaire, F.; Dangla, R. Dynamics of microfluidic droplets. Lab Chip 2010, 10, $2032-2045$.

82. Choi, J.W.; Kang, D.-K.; Park, H.; deMello, A.J.; Chang, S.-I. High-throughput analysis of protein-protein interactions in picoliter-volume droplets using fluorescence polarization. Anal. Chem. 2012, 84, 3849-3854.

83. Theberge, A.B.; Courtois, F.; Schaerli, Y.; Fischlechner, M.; Abell, C.; Hollfelder, F.; Huck, W.T.S. Microdroplets in microfluidics: An evolving platform for discoveries in chemistry and biology. Angew. Chem. Int. Ed. 2010, 49, 5846-5868.

84. Zhang, Y.; Jiang, H.-R. A review on continuous-flow microfluidic PCR in droplets: Advances, challenges and future. Anal. Chim. Acta 2016, 914, 7-16.

85. Beer, N.R.; Hindson, B.J.; Wheeler, E.K.; Sara, B.; Rose, K.A.; Kennedy, I.M.; Colston, B.W. On-chip, real-time, single-copy polymerase chain reaction in picoliter droplets. Anal. Chem. 2007, 79, 8471-8475.

86. Mohr, S.; Zhang, Y.H.; Macaskill, A.; Day, P.J.R.; Barber, R.W.; Goddard, N.J.; Emerson, D.R.; Fielden, P.R. Numerical and experimental study of a droplet-based PCR chip. Microfluid. Nanofluid. 2007, 3, 611-621. 
87. Schaerli, Y.; Wootton, R.C.; Robinson, T.; Stein, V.; Dunsby, C.; Neil, M.A.A.; French, P.M.W.; deMello, A.J.; Abell, C.; Hollfelder, F. Continuous-flow polymerase chain reaction of single-copy DNA in microfluidic microdroplets. Anal. Chem. 2008, 81, 302-306.

88. Kiss, M.M.; Ortoleva-Donnelly, L.; Beer, N.R.; Warner, J.; Bailey, C.G.; Colston, B.W.; Rothberg, J.M.; Link, D.R.; Leamon, J.H. High-throughput quantitative PCR in picoliter droplets. Anal. Chem. 2008, 80, 8975-8981.

89. Leng, X.; Zhang, W.; Wang, C.; Cui, L.; Yang, C.J. Agarose droplet microfluidics for highly parallel and efficient single molecule emulsion PCR. Lab Chip 2010, 10, 2841-2843.

90. Hatch, A.C.; Fisher, J.S.; Tovar, A.R.; Hsieh, A.T.; Lin, R.; Pentoney, S.L.; Yang, D.L.; Lee, A.P. 1-Million droplet array with wide-field fluorescence imaging for digital PCR. Lab Chip 2011, 11, 3838-3845.

91. Zhang, W.; Zhang, W.; Liu, Z.; Li, C.; Zhu, Z.; Yang, C.J. Highly parallel single molecule amplification approach based on agarose droplet PCR for efficient and cost-effective aptamer selection. Anal. Chem. 2012, 84, 350-355.

92. Geng, T.; Novak, R.; Mathies, R.A. Single-cell forensic short tandem repeat typing within microfluidic droplets. Anal. Chem. 2014, 86, 703-712.

93. Beer, N.R.; Wheeler, E.K.; Lee-Houghton, L.; Watkins, N.; Nasarabadi, S.; Hebert, N.; Leung, P.; Arnold, D.W.; Bailey, C.G.; Colston, B.W. On-chip single-copy real-time reverse-transcription PCR in isolated picoliter droplets. Anal. Chem. 2008, 80, 1854-1858.

94. Zhang, H.; Jenkins, G.; Zou, Y.; Zhu, Z.; Yang, C.J. Massively parallel single-molecule and single-cell emulsion reverse transcription polymerase chain reaction using agarose droplet microfluidics. Anal. Chem. 2012, 84, 3599-3606.

95. Geng, T.; Mathies, R.A. Minimizing inhibition of PCR-STR typing using digital agarose droplet microfluidics. Forensic Sci. Int. Genet. 2015, 14, 203-209.

96. Basova, E.Y.; Foret, F. Droplet microfluidics in (bio)chemical analysis. Analyst 2015, 140, $22-38$.

97. Sykes, P.J.; Neoh, S.H.; Brisco, M.J.; Hughes, E.; Condon, J.; Morley, A.A. Quantitation of targets for PCR by use of limiting dilution. Biotechniques 1992, 13, 444-449.

98. White, R.A.; Blainey, P.C.; Fan, S.R.; Quake, H.C. Digital PCR provides sensitive and absolute calibration for high throughput sequencing. BMC Genom. 2009, 10, doi:10.1186/1471-2164-10-116.

99. Sanders, R.; Huggett, J.F.; Bushell, C.A.; Cowen, S.; Scott, D.J.; Foy, C.A. Evaluation of digital PCR for absolute DNA quantification. Anal. Chem. 2011, 83, 6474-6484.

100. Wang, P.; Jing, F.; Li, G.; Wu, Z.; Cheng, Z.; Zhang, J.; Zhang, H.; Jia, C.; Jin, Q.; Mao, H.; et al. Absolute quantification of lung cancer related microRNA by droplet digital PCR. Biosens. Bioelectron. 2015, 74, 836-842.

101. Asiello, P.J.; Baeumner, A.J. Miniaturized isothermal nucleic acid amplification, a review. Lab Chip 2011, 11, 1420-1430.

102. Craw, P.; Balachandran, W. Isothermal nucleic acid amplification technologies for point-of-care diagnostics: A critical review. Lab Chip 2012, 12, 2469-2486.

103. Johne, R.; Müller, H.; Rector, A.; van Ranst, M.; Stevens, H. Rolling-circle amplification of viral DNA genomes using phi29 polymerase. Trends Microbiol. 2009, 17, 205-211.

104. Gill, P.; Ghaemi, A. Nucleic acid isothermal amplification technologies-A review. Nucleosides Nucleotides Nucleic Acids 2008, 27, 224-243.

105. Safavieh, M.; Kanakasabapathy, M.K.; Tarlan, F.; Ahmed, M.U.; Zourob, M.; Asghar, W.; Shafiee, H. Emerging loop-mediated isothermal amplification-based microchip and micro-device technologies for nucleic acid detection. ACS Biomater. Sci. Eng. 2016, 2, 278-294.

106. Mori, Y.; Nagamine, K.; Tomita, N.; Notomi, T. Detection of loop-mediated isothermal amplification reaction by turbidity derived from magnesium pyrophosphate formation. Biochem. Biophys. Res. Commun. 2001, 289, 150-154.

107. Gadkar, V.; Rillig, M.C. Evaluation of loop-mediated isothermal amplification (LAMP) to rapidly detect arbuscular mycorrhizal fungi. Soil Biol. Biochem. 2008, 40, 540-543.

108. Dean, F.B.; Hosono, S.; Fang, L.; Wu, X.; Faruqi, A.F.; Bray-Ward, P.; Sun, Z.; Zong, Q.; Du, Y.; Du, J.; et al. Comprehensive human genome amplification using multiple displacement amplification. Proc. Natl. Acad. Sci. USA 2002, 99, 5261.

109. Silander, K.; Saarela, J. Whole genome amplification with Phi29 DNA polymerase to enable genetic or genomic analysis of samples of low DNA yield. Methods Mol. Biol. 2008, 439, 1-18. 
110. Vincent, M.; Xu, Y.; Kong, H. Helicase-dependent isothermal DNA amplification. EMBO Rep. 2004, 5, 795-800.

111. Motré, A.; Li, Y.; Kong, H. Enhancing helicase-dependent amplification by fusing the helicase with the DNA polymerase. Gene 2008, 420, 17-22.

112. Jeong, Y.J.; Park, K.; Kim, D.E. Isothermal DNA amplification in vitro: The helicase-dependent amplification system. Cell. Mol. Life Sci. 2009, 66, 3325-3336.

113. Lizardi, P.M.; Huang, X.; Zhu, Z.; Bray-Ward, P.; Thomas, D.C.; Ward, D.C. Mutation detection and single-molecule counting using isothermal rolling-circle amplification. Nat. Genet. 1998, 19, 225-232.

114. Liu, D.; Daubendiek, S.L.; Zillman, M.A.; Ryan, K.; Kool, E.T. Rolling circle DNA synthesis: Small circular oligonucleotides as efficient templates for DNA polymerases. J. Am. Chem. Soc. 1996, 118, 1587-1594.

115. Walker, G.T.; Little, M.C.; Nadeau, J.G.; Shank, D.D. Isothermal in vitro amplification of DNA by a restriction enzyme/DNA polymerase system. Proc. Natl. Acad. Sci. USA 1992, 89, 392-396.

116. Fang, X.; Chen, H.; Yu, S.; Jiang, X.; Kong, J. Predicting viruses accurately by a multiplex microfluidic loop-mediated isothermal amplification chip. Anal. Chem. 2010, 83, 690-695.

117. Gansen, A.; Herrick, A.; Dimov, I.K.; Lee, L.; Chiu, D.T. Digital LAMP in a sample self-digitization (SD) chip. Lab Chip 2012, 12, 2247-2254.

118. Duarte, C.; Salm, E.; Dorvel, B.; Reddy, B., Jr.; Bashir, R. On-chip parallel detection of foodborne pathogens using loop-mediated isothermal amplification. Biomed. Microdev. 2013, 15, 821-830.

119. Zhou, Q.-J.; Wang, L.; Chen, J.; Wang, R.-N.; Shi, Y.-H.; Li, C.-H.; Zhang, D.-M.; Yan, X.-J.; Zhang, Y.-J. Development and evaluation of a real-time fluorogenic loop-mediated isothermal amplification assay integrated on a microfluidic disc chip (on-chip LAMP) for rapid and simultaneous detection of ten pathogenic bacteria in aquatic animals. J. Microbiol. Methods 2014, 104, 26-35.

120. Sayad, A.A.; Ibrahim, F.; Uddin, S.M.; Pei, K.X.; Mohktar, M.S.; Madou, M.; Thong, K.L. A microfluidic lab-on-a-disc integrated loop mediated isothermal amplification for foodborne pathogen detection. Sens. Actuators B Chem. 2016, 227, 600-609.

121. Marcy, Y.; Ishoey, T.; Lasken, R.S.; Stockwell, T.B.; Walenz, B.P.; Halpern, A.L.; Beeson, K.Y.; Goldberg, S.M.D.; Quake, S.R. Nanoliter reactors improve multiple displacement amplification of genomes from single cells. PLoS Genet. 2007, 3, 1703-1708.

122. Yang, Y.; Rho, H.S.; Stevens, M.; Tibbe, A.G.J.; Gardeniers, J.G.E.; Terstappen, L.W.M.M. Microfluidic device for DNA amplification of single cancer cells isolated from whole blood by self-seeding micro wells. Lab Chip 2015, 15, 4331-4337.

123. Kaprou, G.D.; Papadakis, G.; Papageorgiou, D.P.; Kokkoris, G.; Papadopoulos, V.; Kefala, I.; Gizeli, E.; Tserepi, A. Miniaturized devices for isothermal DNA amplification addressing DNA diagnostics. Microsyst. Technol. 2016, 22, 1529-1534.

124. Shi, D.; Huang, J.; Chuai, Z.; Chen, D.; Zhu, X.; Wang, H.; Peng, J.; Wu, H.; Huang, Q.; Fu, W. Isothermal and rapid detection of pathogenic microorganisms using a nano rolling circle amplification-surface plasmon resonance biosensor. Biosens. Bioelectron. 2014, 62, 280-287.

125. Ma, X.; Xu, W.; Chen, C.; Lu, Z.; Li, J. A microfabrication-free nanoliter droplet array for nucleic acid detection combined with isothermal amplification. Analyst 2015, 140, 4370-4373.

126. Kalsi, S.; Valiadi, M.; Tsaloglou, M.-N.; Parry-Jones, L.; Jacobs, A.; Watson, R.; Turner, C.; Amos, R.; Hadwen, B.; Buse, J.; et al. Rapid and sensitive detection of antibiotic resistance on a programmable digital microfluidic platform. Lab Chip 2015, 15, 3065-3075.

127. Santiago-Felipe, S.; Tortajada-Genaro, L.A.; Puchades, R.; Maquieira, Á. Parallel solid-phase isothermal amplification and detection of multiple DNA targets in microliter-sized wells of a digital versatile disc. Microchim. Acta 2016, 183, 1195-1202.

128. Kunze, A.; Dilcher, M.; Abd El Wahed, A.; Hufert, F.; Niessner, R.; Seidel, M. On-chip isothermal nucleic acid amplification on flow-based chemiluminescence microarray analysis platform for the detection of viruses and bacteria. Anal. Chem. 2016, 88, 898-905.

129. Nagamine, K.; Hase, T.; Notomi, T. Accelerated reaction by loop-mediated isothermal amplification using loop primers. Mol. Cell. Probes 2002, 16, 223-229.

130. Notomi, T.; Okayama, H.; Masubuchi, H.; Yonekawa, T.; Watanabe, K.; Amino, N.; Hase, T. Loop-mediated isothermal amplification of DNA. Nucleic Acids Res. 2000, 28, e63. 
131. Mori, Y.; Kitao, M.; Tomita, N.; Notomi, T. Real-time turbidimetry of LAMP reaction for quantifying template DNA. J. Biochem. Biophys. Methods 2004, 59, 145-157.

132. Cai, T.; Lou, G.Q.; Yang, J.; Xu, D.; Meng, Z.H. Development and evaluation of real-time loop-mediated isothermal amplification for hepatitis B virus DNA quantification: A new tool for HBV management. J. Clin. Virol. 2008, 41, 270-276.

133. Deguo, W.; Guicheng, H.; Fugui, W.; Yonggang, L.; Daxi, R. Drawback of loop-mediated isothermal amplification. Afr. J. Food Sci. 2008, 2, 83-86.

134. Luo, J.; Fang, X.; Ye, D.; Li, H.; Chen, H.; Zhang, S.; Kong, J. A real-time microfluidic multiplex electrochemical loop-mediated isothermal amplification chip for differentiating bacteria. Biosens. Bioelectron. 2014, 60, 84-91.

135. Watthanapanpituck, K.; Kiatpathomchai, W.; Chu, E.; Panvisavas, N. Identification of human DNA in forensic evidence by loop-mediated isothermal amplification combined with a colorimetric gold nanoparticle hybridization probe. Int. J. Legal Med. 2014, 128, 923-931.

136. illustra GenomiPhi V2 DNA Amplification Kit, 2006. Available online: https://www.gelifesciences. com/gehcls_images/GELS/Related\%20Content/Files/1314774443672/litdocGPHI_V2_25660030_revB_ 20110831102610.pdf (accessed on 1 August 2016).

137. Kumar, G.; Garnova, E.; Reagin, M.; Vidali, A. Improved multiple displacement amplification with Phi 29 DNA polymerase for genotyping of single human cells. BioTechniques 2008, 44, 879-890.

138. Salas, M.; Blanco, L.; Lázaro, J.M.; de Vega, M. The bacteriophage $\phi 29$ DNA polymerase. IUBMB Life 2008, $60,82-85$.

139. Ballantyne, K.N.; van Oorschot, R.A.H.; John Mitchell, R.; Koukoulas, I. Molecular crowding increases the amplification success of multiple displacement amplification and short tandem repeat genotyping. Anal. Biochem. 2006, 355, 298-303.

140. Ballantyne, K.N.; van Oorschot, R.A.H.; Mitchell, R.J. Comparison of two whole genome amplification methods for STR genotyping of LCN and degraded DNA samples. Forensic Sci. Int. 2007, 166, 35-41.

141. Singer, V.L.; Jones, L.J.; Yue, S.T.; Haugland, R.P. Characterization of PicoGreen reagent and development of a fluorescence-based solution assay for double-stranded DNA quantitation. Anal. Biochem. 1997, 249, 228-238.

142. Tanner, N.A.; Zhang, Y.; Evans, T.C., Jr. Visual detection of isothermal nucleic acid amplification using pH-sensitive dyes. BioTechniques 2015, 59, 59-68.

143. Rodriguez-Manzano, J.; Karymov, M.A.; Begolo, S.; Selck, D.A.; Zhukov, D.V.; Jue, E.; Ismagilov, R.F. Reading out single-molecule digital RNA and DNA isothermal amplification in nanoliter volumes with unmodified camera phones. ACS Nano 2016, 10, 3102-3113.

144. Molecular Probes ${ }^{\circledR}$. The Molecular Probes ${ }^{\circledR}$ Handbook, 2012. Available online: http:/ /www.invitrogen. $\mathrm{com} / \mathrm{site} / \mathrm{us} / \mathrm{en} /$ home/References/Molecular-Probes-The-Handbook.html (accessed on 3 May 2016).

145. Sang, F.; Ren, J. Capillary electrophoresis of double-stranded DNA fragments using a new fluorescence intercalating dye EvaGreen. J. Sep. Sci. 2006, 29, 1275-1280.

146. Ross, J.S.; Cronin, M. Whole cancer genome sequencing by next-generation methods. Am. J. Clin. Pathol. 2011, 136, 527-539.

147. Liu, L.; Li, Y.; Li, S.; Hu, N.; He, Y.; Pong, R.; Lin, D.; Lu, M.; Law, L. Comparison of next-generation sequencing systems. BioMed Res. Int. 2012, 2012, 1-11.

148. Liu, P.; Scherer, J.R.; Greenspoon, S.A.; Chiesl, T.N.; Mathies, R.A. Integrated sample cleanup and capillary array electrophoresis microchip for forensic short tandem repeat analysis. Forensic Sci. Int. Genet. 2011, 5, 484-492.

149. Chen, D.; Mauk, M.; Qiu, X.; Liu, C.; Kim, J.; Ramprasad, S.; Ongagna, S.; Abrams, W.R.; Malamud, D.; Corstjens, P.L.; et al. An integrated, self-contained microfluidic cassette for isolation, amplification, and detection of nucleic acids. Biomed. Microdev. 2010, 12, 705-719.

150. Le Roux, D.; Root, B.E.; Reedy, C.R.; Hickey, J.A.; Scott, O.N.; Bienvenue, J.M.; Landers, J.P.; Chassagne, L.; de Mazancourt, P. DNA analysis using an integrated microchip for multiplex PCR amplification and electrophoresis for reference samples. Anal. Chem. 2014, 86, 8192-8199.

151. Pascali, J.P.; Bortolotti, F.; Tagliaro, F. Recent advances in the application of CE to forensic sciences, an update over years 2009-2011. Electrophoresis 2012, 33, 117-126. 
152. Mitnik, L.; Carey, L.; Burger, R.; Desmarais, S.; Koutny, L.; Wernet, O.; Matsudaira, P.; Ehrlich, D. High-speed analysis of multiplexed short tandem repeats with an electrophoretic micro-device. Electrophoresis 2002, 23, 719-726.

153. Chen, Y.; Young Choi, J.; Jin Choi, S.; Seo, T.S. Sample stacking capillary electrophoretic micro-device for highly sensitive mini Y short tandem repeat genotyping. Electrophoresis 2010, 31, 2974-2980.

154. Date-Chong, M.; Hudlow, W.R.; Buoncristiani, M.R. Evaluation of the RapidHIT 200 and RapidHIT GlobalFilerExpress kit for fully automated STR genotyping. Forensic Sci. Int. Genet. 2016, 23, 1-8.

155. Aboud, M.J.; Gassmann, M.; McCord, B. Ultrafast STR separations on short-channel microfluidic systems for forensic screening and genotyping. J. Forensic Sci. 2015, 60, 1164-1170.

156. Frippiat, C.; Zorbo, S.; Leonard, D.; Marcotte, A.; Chaput, M.; Aelbrecht, C.; Noel, F. Evaluation of novel forensic DNA storage methodologies. Forensic Sci. Int. Genet. 2011, 5, 386-392.

157. Hamilton Company. Netherlands Forensic Institute Orders BiOS Automated Biobanking System, 2012. Available online: http://www.hamiltoncompany.com/about-us/news-and-events/press-releases / 2012-press-releases/netherlands-forensic-institute-orders-bios-automated-biobanking-system (accessed on 13 May 2016).

158. Lee, S.B.; Clabaugh, K.C.; Silva, B.; Odigie, K.O.; Coble, M.D.; Loreille, O.; Scheible, M.; Fourney, R.M.; Stevens, J.; Carmody, G.R.; et al. Assessing a novel room temperature DNA storage medium for forensic biological samples. Forensic Sci. Int. Genet. 2012, 6, 31-40.

159. Ahn, C.H.; Choi, J.W.; Beaucage, G.; Nevin, J.; Lee, J.B.; Puntambekar, A.; Lee, R.J.Y. Disposable smart lab on a chip for point-of-care clinical diagnostics. Proc. IEEE 2004, 92, 154-173.

160. Abgrall, P.; Gue, A.M. Lab-on-chip technologies: Making a microfluidic network and coupling it into a complete microsystem: A review. J. Micromech. Microeng. 2007, 17, R15.

161. Cho, Y.K.; Kim, J.; Lee, Y.; Kim, Y.A.; Namkoong, K.; Lim, H.; Oh, K.W.; Kim, S.; Han, J.; Park, C.; et al. Clinical evaluation of micro-scale chip-based PCR system for rapid detection of hepatitis $\mathrm{B}$ virus. Biosens. Bioelectron. 2006, 21, 2161-2169.

162. Aboud, M.J.; Gassmann, M.; McCord, B.R. The development of mini pentameric STR loci for rapid analysis of forensic DNA samples on a microfluidic system. Electrophoresis 2010, 31, 2672-2679.

163. Geissler, M.; Beauregard, J.A.; Charlebois, I.; Isabel, S.; Normandin, F.; Voisin, B.; Boissinot, M.; Bergeron, M.G.; Veres, T. Extraction of nucleic acids from bacterial spores using bead-based mechanical lysis on a plastic chip. Eng. Life Sci. 2011, 11, 174-181.

164. Ogura, M.; Agata, Y.; Watanabe, K.; McCormick, R.M.; Hamaguchi, Y.; Aso, Y.; Mitsuhashi, M. RNA chip: Quality assessment of RNA by microchannel linear gel electrophoresis in injection-molded plastic chips. Clin. Chem. 1998, 44, 2249.

165. Mueller, O.; Hahnenberger, K.; Dittmann, M.; Yee, H.; Dubrow, R.; Nagle, R.; Ilsley, D. A microfluidic system for high-speed reproducible DNA sizing and quantitation. Electrophoresis 2000, 21, 128-134.

166. Pekin, D.; Skhiri, Y.; Baret, J.C.; le Corre, D.; Mazutis, L.; Salem, C.B.; Millot, F.; El Harrak, A.; Hutchison, J.B.; Larson, J.W.; et al. Quantitative and sensitive detection of rare mutations using droplet-based microfluidics. Lab Chip 2011, 11, 2156-2166.

167. Fang, W.F.; Ting, S.C.; Hsu, C.W.; Chen, Y.T.; Yang, J.T. Locally enhanced concentration and detection of oligonucleotides in a plug-based microfluidic device. Lab Chip 2012, 12, 923-931.

168. Marcus, J.S.; Anderson, W.F.; Stephen, R. Parallel picoliter RT-PCR assays using microfluidics. Anal. Chem. 2006, 78, 956-958.

169. Deal, K.S.; Easley, C.J. A self-regulated, droplet-based sample chopper for microfluidic absorbance detection. Anal. Chem. 2011, 84, 1510-1516.

170. Hatch, A.C.; Fisher, J.S.; Pentoney, S.L.; Yang, D.L.; Lee, A.P. Tunable 3D droplet self-assembly for ultra-high-density digital micro-reactor arrays. Lab Chip 2011, 11, 2509-2517.

171. Yang, P.; Ji, J.; Guo, L.; Zhao, Y.; Ji, C.; Liu, B. Interfacial organic synthesis in a simple droplet-based microfluidic system. Lab Chip 2012, 12, 1373-1377.

172. Morganti, E.; Collini, C.; Potrich, C.; Ress, C.; Adami, A.; Lorenzelli, L.; Pederzolli, C. A micro polymerase chain reaction module for integrated and portable DNA analysis systems. J. Sens. 2011, 2011, 1-7.

173. Crabtree, H.J.; Lauzon, J.; Morrissey, Y.C.; Taylor, B.J.; Liang, T.; Johnstone, R.W.; Stickel, A.J.; Manage, D.P.; Atrazhev, A.; Backhouse, C.J.; et al. Inhibition of on-chip PCR using PDMS-glass hybrid microfluidic chips. Microfluid. Nanofluid. 2012, 13, 383-398. 
174. Heyries, K.A.; Tropini, C.; van Insberghe, M.; Doolin, C.; Petriv, O.I.; Singhal, A.; Leung, K.; Hughesman, C.B.; Hansen, C.L. Megapixel digital PCR. Nat. Methods 2011, 8, 649-651.

175. Zhu, Q.; Qiu, L.; Yu, B.; Xu, Y.; Gao, Y.; Pan, T.; Tian, Q.; Song, Q.; Jin, W.; Jin, Q.; et al. Digital PCR on an integrated self-priming compartmentalization chip. Lab Chip 2014, 14, 1176-1185.

176. Nakano, M.; Komatsu, J.; Matsuura, S.; Takashima, K.; Katsura, S.; Mizuno, A. Single-molecule PCR using water-in-oil emulsion. J. Biotechnol. 2003, 102, 117-124.

177. Lagally, E.T.; Simpson, P.C.; Mathies, R.A. Monolithic integrated microfluidic DNA amplification and capillary electrophoresis analysis system. Sens. Actuators B Chem. 2000, 63, 138-146.

178. Chen, X.; Cui, D.; Liu, H.; Li, C.; Chen, J. Continuous flow microfluidic device for cell separation, cell lysis and DNA purification. Anal. Chim. Acta 2007, 584, 237-243.

179. Liu, P.; Li, X.; Greenspoon, S.A.; Scherer, J.R.; Mathies, R.A. Integrated DNA purification, PCR, sample cleanup, and capillary electrophoresis microchip for forensic human identification. Lab Chip 2011, 11, 1041-1048.

180. Jha, S.K.; Chand, R.; Han, D.; Jang, Y.-C.; Ra, G.-S.; Kim, J.S.; Nahm, B.-H.; Kim, Y.-S. An integrated PCR microfluidic chip incorporating aseptic electrochemical cell lysis and capillary electrophoresis amperometric DNA detection for rapid and quantitative genetic analysis. Lab Chip 2012, 12, 4455-4464.

181. Lounsbury, J.A.; Karlsson, A.; Miranian, D.C.; Cronk, S.M.; Nelson, D.A.; Li, J.I.; Haverstick, D.M.; Kinnon, P.; Saul, D.J.; Landers, J.P. From sample to PCR product in under 45 minutes: A polymeric integrated micro-device for clinical and forensic DNA analysis. Lab Chip 2013, 13, 1384-1393.

182. Oblath, E.A.; Hampton Henley, W.; Alarie, J.P.; Ramsey, J.M. A microfluidic chip integrating DNA extraction and real-time PCR for the detection of bacteria in saliva. Lab Chip 2013, 13, 1325-1332.

183. Northrup, M.A.; Benett, B.; Hadley, D.; Landre, P.; Lehew, S.; Richards, J.; Stratton, P. A miniature analytical instrument for nucleic acids based on micromachined silicon reaction chambers. Anal. Chem. 1998, 70, 918-922.

184. Jung, W.; Yang, J.; Barrett, M.; Duane, B.; Brooks, C.; Hurth, C.; Nordquist, A.; Smith, S.; Zenhausern, F. Recent improvement in miniaturization and integration of a DNA analysis system for rapid forensic analysis (MiDAS). J. Forensic Investig. 2014, 2, 7.

185. Liu, P.; Yeung, S.H.I.; Crenshaw, K.A.; Crouse, C.A.; Scherer, J.R.; Mathies, R.A. Real-time forensic DNA analysis at a crime scene using a portable microchip analyzer. Forensic Sci. Int. Genet. 2008, 2, 301-309.

186. Xu, J.; Lv, X.; Wei, Y.; Zhang, L.; Li, Y.; and Deng, R.; Xu, X. Air bubble resistant and disposable microPCR chip with a portable and programmable device for forensic test. Sens. Actuators B Chem 2015, 212, 472-480.

187. Romsos, E.L.; Vallone, P.M. Rapid PCR of STR markers: Applications to human identification. Forensic Sci. Int. Genet. 2015, 18, 90-99.

188. Kloosterman, A.D.; Mckeown, B.; Elliott, K.; Gardeniers, J.G.E.; Bruijns, B.B.; Mapes, A.A. Workshop: Mobile DNA-Technologies, 2012. Available online: http://www.forensic.to/abstract_book_ eafs2012.pdf (accessed on 27 April 2016).

189. LGC Forensics. ParaDNA, 2011. Available online: http://paradna.lgcforensics.com/ (accessed on 3 May 2016).

190. Ball, G.; Dawnay, N.; Stafford-Allen, B.; Panasiuk, M.; Rendell, P.; Blackman, S.; Duxbury, N.; Wells, S. Concordance study between the ParaDNA Intelligence Test, a Rapid DNA profiling assay, and a conventional STR typing kit (AmpFISTR SGM Plus. Forensic Sci. Int. Genet. 2015, 16, 48-51.

191. Blackman, S.; Dawnay, N.; Ball, G.; Stafford-Allen, B.; Tribble, N.; Rendell, P.; Neary, K.; Hanson, E.K.; Ballantyne, J.; Kallifatidis, B.; et al. Developmental validation of the ParaDNA ${ }^{\circledR}$ Intelligence System-A novel approach to DNA profiling. Forensic Sci. Int. Genet. 2015, 17, 137-148.

192. IntegenX. RapidHIT, 2014. Available online: http://integenx.com/ (accessed on 3 May 2016).

193. Hennessy, L.K.; Franklin, H.; Li, Y.; Buscaino, J.; Chear, K.; Gass, J.; Mehendale, N.; Williams, S.; Jovanovich, S.; Harris, D.; et al. Developmental validation studies on the RapidHIT Human DNA Identification System. Forensic Sci. Int. Genet. Suppl. Ser. 2013, 4, e7-e8.

194. Gangano, S.; Elliott, K.; Anoruo, K.; Gass, J.; Buscaino, J.; Jovanovich, S.; Harris, D. DNA investigative lead development from blood and saliva samples in less than two hours using the RapidHIT Human DNA Identification System. Forensic Sci. Int. Genet. Suppl. Ser. 2013, 4, e43-e44.

195. Verheij, S.; Clarisse, L.; van den Berge, M; Sijen, T. RapidHIT 200, a promising system for rapid DNA analysis. Forensic Sci. Int. Genet. Suppl. Ser. 2013, 4, e254-e255. 
196. NEC. By Technologies: Portable DNA Analyzer, 2015. Available online: http://www.nec.com/en/global/ solutions/security/technologies/dna_analyzer_technologies.html (accessed on 9 May 2016).

197. NEC. By Products: Portable DNA Analyzer, 2015. Available online: http://www.nec.com/en/global/ solutions/security/products/portable_dna_analyzer.html (accessed on 9 May 2016).

(c) 2016 by the authors; licensee MDPI, Basel, Switzerland. This article is an open access article distributed under the terms and conditions of the Creative Commons Attribution (CC-BY) license (http://creativecommons.org/licenses/by/4.0/). 